Discussion Paper No. 634

\title{
PRICE BUBBLES SANS DIVIDEND ANCHORS: EVIDENCE FROM LABORATORY STOCK MARKETS
}

\author{
Shinichi Hirota \\ and \\ Shyam Sunder
}

May 2005

The Institute of Social and Economic Research Osaka University

6-1 Mihogaoka, Ibaraki, Osaka 567-0047, Japan 


\title{
PRICE BUBBLES SANS DIVIDEND ANCHORS: EVIDENCE FROM LABORATORY STOCK MARKETS
}

\author{
Shinichi Hirota * Shyam Sunder**
}

\begin{abstract}
We experimentally explore how investor decision horizons influence the formation of stock prices. We find that in long-horizon sessions, where investors collect dividends till maturity, prices converge to the fundamental levels derived from dividends through backward induction. In short-horizon sessions, where investors exit the market by receiving the price (not dividends), prices levels and paths become indeterminate and lose dividend anchors; investors tend to form their expectations of future prices by forward, not backward, induction. These laboratory results suggest that investors' short horizons and the consequent difficulty of backward induction are important contributors to the emergence of price bubbles.
\end{abstract}

JEL classification: G12; C91

Keywords: stock price bubbles, short-term investors, backward induction, and market experiments

(C) Copyright 2001-5. All rights reserved.

January 2005. Please do not quote without the authors' permission. Comments are welcome. We want to thank the workshop participants at Carnegie Mellon University, Cornell University, University of Guelph, University of Houston, University of Iowa, Kansas University, University of Mannheim, University of Maryland, Osaka University, Sophia University, Tokyo Institute of Technology, University of Utah, Waseda University, Yale School of Management, University of Zurich, Annual Meetings of the Economic Science Association, the Nippon Finance Association, the Western Finance Association, and the European Finance Association for their helpful comments and suggestions on the earlier drafts of this paper. We also thank Brian Lee and Judy Carmel for their assistance.

* School of Commerce, Waseda University Institute of Social and Economic Research, Osaka University, shirota@waseda.jp

** School of Management, Yale University, shyam.sunder@yale.edu 


\section{PRICE BUBBLES SANS DIVIDEND ANCHORS: EVIDENCE FROM LABORATORY STOCK MARKETS}

\section{Introduction}

This paper uses a laboratory experiment to explore how investors' decision horizons affect the formation of stock prices. It has long been argued that speculation by short-term investors induces price volatility. Speculators are concerned primarily with capital gains; the dividends paid during their short investment horizon are relatively insignificant. Expectations of capital gains depend on higher order expectations susceptible to cascading or mass psychology of the market. In markets populated by short-term investors, the argument goes, prices tend to lose their dividend anchors, can take any value depending on such expectations, and are therefore susceptible to price indeterminacy and bubbles.

This conventional wisdom is not necessarily accepted in today's finance textbooks. We teach that the prices of securities are determined by their fundamental values - the sum of the discounted value of future dividends-irrespective of investors' time horizons. Even short-term investors are assumed to backward induct from future cash flows to arrive at the fundamental value of securities at the present time.

On the other hand, some theoretical research suggests that such backward induction may fail, and short-term speculative trading may give rise to bubbles. Rational bubble models [Blanchard and Watson 1982, Tirole 1985] consider indeterminacy of price levels of infinite maturity securities without terminal values. Short-term investors have no values from which they can backward induct. In addition, recent theoretical models argue that when investors have heterogeneous information and/or their rationality is not common knowledge, shortterm investors may find it difficult to backward induct and security prices may diverge from their fundamentals [e.g., DeLong et al. 1990a, 1990b, Froot, Scharfstein, and Stein 1992, Dow and Gorton 1994, Allen, Morris, and Shin 2002]. Unlike psychological theories of mass 
hysteria or limited cognition, these models show that indeterminacy of security prices can arise because even rational investors may not have the knowledge, beliefs, and coordination devices necessary for prices to coincide with the fundamental values.

From these models, we conjecture that the difficulty of backward induction originating in investor short-horizons is a primary source of price bubbles. However, little empirical evidence exists to support this theoretical body of work. Since fundamental values of equities are rarely known, empirical studies of price bubbles in data from the field face the difficult challenge of separating bubbles from the possibility that the fundamental model is misspecified. ${ }^{1}$

Laboratory experiments can address this problem by letting the experimenter assign parameters to subjects to control the fundamental value. Smith, Suchanek and Williams [1987] showed that bubbles can arise in simple laboratory asset markets and conjectured that investors may conduct speculative trades aiming to sell the security to others at higher prices. Lei, Noussair and Plott's [2001] experiment, however, rejected this conjecture. It showed that bubbles arise even when investors cannot engage in speculative trades; bubbles arise from errors in investors' decision making itself. In contrast to these works, the objective of our experiment is to explore how investors decision horizons influence stock prices. To attain this aim, we control not only the fundamental value but also the investors' decision horizon relative to the maturity of the security. We report on the design and results of such an experiment.

The main treatment in the experiment is differentiated by long- and short-horizon investors. In the long-horizon sessions, the investors' decision horizon extends to the date of maturity of the security, at which time they receive an exogenously specified dividend. In the short-horizon sessions, investors' decision horizon ends well before the date of maturity, and

\footnotetext{
${ }^{1}$ See, Stiglitz (1990), and Fama (1991). LeRoy (2003) also states in a recent survey article that "One would like to see the development of empirical tests that could distinguish between bubbles and misspecification.”(p. 25)
} 
they exit by receiving the prices (an estimate of expected future prices) endogenous to the session. This price is the average of the next period's predicted price submitted by a separate group of subjects who watch, but do not participate in, trading and who get paid based on the ex post accuracy of their predictions. Thus, this price is not necessarily linked to the exogenously specified terminal dividend - the fundamental value-via backward induction. Following the abovementioned models, we predict that the security prices should deviate from the fundamentals in the short- but not in the long-horizon sessions. In addition to the main treatment, we examine the robustness of any effects of the main treatment with respect to several other variations described later.

We find that security prices tend to form bubbles in short-, but not in long-horizon markets. With short investor horizons, prices lose dividend anchors and their levels and paths become indeterminate. While parts of some paths are consistent with rational bubbles, others exhibit positive feedback loops [Shiller 2000]. The results are consistent with the proposition that when they are unable to backward induct from dividend anchors, investors tend to form their expectations of future prices by forward induction using first-order adaptive or trend processes. In these markets, allocative efficiency is unpredictable, and the cross-sectional dispersion of wealth increases with the deviation of prices from fundamentals. In contrast, prices in markets populated by long-horizon investors tend to converge to the fundamentals.

These laboratory results support the proposition that the difficulty of backward induction by short-horizon investors is a critical factor in the generation of bubbles. They also suggest that bubbles are more likely to occur in markets for securities with longer duration or maturity, and more uncertain dividends. These laboratory findings are consistent with the stylized facts of the susceptibility of high-growth and new technology stocks to bubble formation. 
The remainder of the paper is organized as follows: Section II reviews the literature on linkages among investment horizon, backward induction, and the emergence of bubbles. Section III describes the experimental design and procedures. Section IV reports our laboratory results, and Section V discusses the implications.

\section{Investment Horizons and the Security Valuation}

In standard theory, the security prices are, or tend toward the fundamental values - the sum of discounted present value of expected future dividends - irrespective of investors' decision horizons. This proposition is derived through backward induction from future dividends to present value. We argue that the backward induction may fail and the prices in markets populated by short-term investors deviate from the fundamentals and form bubbles. The discussion below helps guide the design of a critical laboratory experiment to examine the conditions that generate price bubbles or indeterminacy in stock markets.

Let us start with considering a security that matures at time $t+m$. For simplicity, the security pays only a terminal dividend $D$ at time $t+m$. Assuming a zero discount rate and riskneutral investors, the fundamental value of the security at time $t$ is:

$$
F_{t}=E_{t}(D)
$$

where $E_{t}($.$) is investors' homogeneous expectation at time t$.

\section{II-1. Long-term investor's valuation}

We define a long-term investor as one whose investment horizon is longer than or equal to $m$. This investor holds the security until its maturity and receives the terminal dividend $D$ at $t+m$. The value of the security to the investor at time $t, V_{t}$ (and its price $P_{t}$ in a market populated by such homogenous investors) is:

$$
P_{t}=V_{t}=E_{t}(D)
$$

This price is equal to the fundamental value $F_{t}$. 


\section{II-2. Short-term investor's valuation}

Next consider short-term investors with investment horizon $k<m$, who must sell the security before its date of maturity. The investor buys the security at time $t$, holds it for $k$ periods, and sells it at $t+k$. The value of the security to this investor and its price $P_{t}$ in a market populated by such homogenous investors is:

$$
P_{t}=V_{t}=E_{t}\left(P_{t+k}\right)
$$

where $P_{t+k}$ is the stock price at $t+k$. Equation (3) indicates that price $P_{t}$ depends on the investor's expectation of the future sales price, $E_{t}\left(P_{t+k}\right)$. It opens the possibility that when investors' horizon is shorter than the maturity, the security price may not be equal to the fundamental value $F_{t}$.

In the standard backward induction treatment in finance, even in markets populated by short-term investors, $P_{t}$ should be equal to $F_{t}$ via backward induction. $k$ periods before the maturity date, the price $P_{t+m-k}$ should be equal to the investor's expectation at $t+m-k$ of the terminal dividend, $E_{t+m-k}(D)$. If the investor at time $t+m-2 k$ knows this, $P_{t+m-2 k}$ should be equal to his expectation of $P_{t+m-k}$, which is $E_{t+m-2 k}\left(E_{t+m-k}(D)\right)$. If the investor at time $t+m-3 k$ knows this, $P_{t+m-3 k}$ should be equal to $E_{t+m-3 k}\left(E_{t+m-2 k}\left(E_{t+m-k}(D)\right)\right)$. Repeating this process back to $t$, we get

$$
P_{t}=E_{t}\left(E _ { t + k } \left(E_{t+2 k}\left(\ldots\left(E_{t+m-k}(D)\right) \ldots\right) .\right.\right.
$$

Assuming that all investors across generations are homogenous in information sets, we can use the law of iterated expectations and obtain $P_{t}=E_{t}(D)=F_{t}$.

\section{II-3. Difficulty of backward induction}

The possibility of the failure of the backward induction argument in markets with short-term investors as a source of price bubbles has been suggested in the rational bubbles literature [Blanchard and Watson 1982, and Tirole 1982, 1985]: when the maturity of the

\footnotetext{
${ }^{2}$ For simplicity, we assume that $n k=m$ ( $n$ is any integral number).
} 
security extends indefinitely $(m \rightarrow \infty)$, the investor cannot obtain the terminal value and backward induction becomes impossible. Prices become indeterminate and may deviate from fundamentals. It is also known that this indeterminacy may arise even when the maturity is finite, provided that there are an unlimited number of trading opportunities [Allen and Gorton 1993].

Second, when investors have heterogeneous beliefs, the law of iterated expectations is no longer applicable. In order to backward induct the future sales price in that case, investors must form higher-order expectations: If each generation of investors have a $k$-period investment horizon, the investors entering at $t$ must decide on the basis of what they believe the investors at $t+k$ expect what investors at $t+2 k$ expect...and so on till $t+m$. Froot, Scharfstein, and Stein [1992] and Allen, Morris, and Shin [2002] consider the case where short-term investors have only limited information about the future investor's expectations. They show that the backward induction argument fails and that stock prices are affected by noisy or irrelevant public information. ${ }^{3}$

Third, the backward induction argument assumes common knowledge of investors' rationality: investors are not only rational but also know that other investors are rational as well. Recent theoretical research illustrates that when the common knowledge assumption of rationality does not hold, the backward induction argument fails and stock prices deviate from fundamentals. Delong et al. [1990a, 1990b] show that when there are noise traders in the market, rational investors with short-term horizon expect future mis-pricing, and might not engage in arbitrage even if they know that the current price deviates from the fundamentals. Dow and Gorton [1994] argue that when there is uncertainty about the existence of informed rational arbitrageurs in the future, the current traders fail to backward induct the sales price from the future dividends.

\footnotetext{
${ }^{3}$ Allen, Morris, and Postlewaite (1993) argue that even in markets with long-term investors the backward
} 
We examine the empirical relevance of these theoretical ideas. Do short investment horizons, and consequent difficulty of backward induction when there is no reasonable basis to form common knowledge expectations of higher orders, give rise to price bubbles and indeterminacy? We test this hypothesis with the following laboratory experiment.

\section{The Experimental Design}

We created double auction markets for trading units of a security on a computer network in a laboratory. The security paid a single liquidating dividend to its holders at the end of its life, which was divided into many trading periods of three minutes each. Participating subjects were randomly assigned to one of two roles - investors and predictors. Each investor was endowed with 10 securities and 10,000 points of "cash" at the beginning of period 1, and could trade freely through the multiple periods without going short on securities or "cash." At the end of the session, the securities held by investors were liquidated by paying them either a dividend or a predicted price (as described later under the Main Treatment). The investors could make money through trading and terminal liquidation of their securities.

The predictors studied all the instructions given to the investors. They did not get endowments of cash or securities, could not trade, and only knew the range of the traders' terminal dividends. At the end of each period they were asked to predict the average price of the security transactions for the following period. Their earnings depended on the accuracy of their predictions. In addition to these earnings, all subjects earned \$3 (in Sessions 1-6) or $\$ 5$ (in Sessions 7-11) if they arrived in the laboratory punctually.

\section{III-1. Main Treatment: Long or Short Investment Horizons}

In five sessions (numbered chronologically 3, 4, 5, 6, and 7 in Table 1), the investors were informed that the security would pay a terminal dividend (pre-written on their 
respective cards) at the end of period 15 and that the session would end at that time. This environment is designed to correspond to that of the long-term investors in Section II-1: since the investors' investment horizon can extend to the security's maturity, we call these longhorizon sessions. In these sessions, if the investors buy (sell) securities depending on whether the price is lower (higher) than the terminal dividend, the price would converge to the fundamental value of the security, $P_{t}=F_{t}$. If some investors speculate seeking capital gains within the 15-period session, and push the prices away from the fundamental value, such deviations would also give the long-term investors an opportunity to make profits by arbitraging between such deviations and terminal dividends.

In six sessions (numbered 1, 2, 8, 9, 10 and 11 in Table 1), investors were informed that their securities would pay a terminal dividend at the end of period 30 if the session were to end in period 30 . They were also informed that the session would end at a period written down inside a sealed envelope, and this period is very likely to be less than 30 . Although they were not informed about the real number of periods in the session until it was actually terminated, they could have estimated that the length of time for which they had been recruited into the laboratory would end well before Period $30 .{ }^{4}$ If the session ended earlier than period 30 (as it always did), for each security, investors would receive the average transaction price predicted for the period immediately following the termination. We call these short-horizon sessions because this treatment was designed to capture the environment of markets with the short-term investors described in Section II-3: investors' horizon ends before the security matures, and they may find it difficult to backward induct the sales price when exiting the market from future dividends.

\footnotetext{
${ }^{4}$ When subjects were recruited, they were told to participate in an experiment in market decision-making for 2-3 hours in total. At the beginning of the session in a laboratory, subjects knew that (i) they had already spent about an hour and half for instruction and trial sessions, and (ii) one period was three minutes long followed by the paper work for a minute or two. Thus they could predict that the session would end well before period 30.
} 
As we mentioned in Section II-3, recent bubble literature illustrates several factors for breaking the link between investors' expectation of sale prices and the future dividends (fundamentals): Froot, Scharfstein, and Stein [1992] and Allen, Morris and Shin [2002] point out investors' limited information about the expectations of the subsequent generations of investors; Delong et al. [1990a, 1990b] and Dow and Gorton [1994] suppose the existence of irrational future investors; the rational bubble models [Blanchard and Watson 1982, Tirole $1982,1985]$ suggest that the expected sale prices may include the bubble term not linked to the future dividends at all.

Our short-horizon sessions try to realize this breach of the link in the laboratory without using either irrationality or a bubble in future dividends. Since the investors would receive the terminal dividend if their investment horizons were long enough to include period 30, this dividend can be considered the fundamental value. However, investors know that the session is very likely to end before Period 30 and when the session terminates they are paid off the prevailing market price (predicted price) for each security; there is no sensible way to expect this ending price by backward induction. In this manner, we intended to break, or substantially weaken the link between the expected future prices and the terminal dividends ${ }^{5}$. In such an environment, the security prices would lose their dividend anchors, opening up the possibility that they would deviate from the fundamental values.

In this market, the experimenter provides the liquidity at the end of the session: investors' security holdings would be bought back by the experimenter at the prevailing market price, as proxied by the average of price predictions. In this environment, investors can exit the laboratory market without any impact on the price. We introduced this treatment

\footnotetext{
${ }^{5}$ Other variations are also possible. An announcement that the terminal dividend would be paid at period 30 but the session will end earlier, say at period 15, for sure, would break the link completely. Alternatively, the session could be terminated with a common knowledge probability distribution to retain a weak but well-specified link. For example, we could have announced that there will be a ten percent chance that the session will be terminated at the end of period 10,11,12,13, or 14, with the predicted price payoff; if the session goes to period 15 , it will be terminated with the pre-specified dividend payoff.
} 
because liquidity is well-documented feature of stock markets such as New York Stock Exchange. We use the average prediction for the period following the last period, instead of the actual market price in the last period, as the ending value of the securities. This helps prevent the manipulation of the ending value by investors with large security holdings. ${ }^{6}$

The short-horizon sessions are especially relevant to the markets for high growth stocks whose dividends may be paid in remote future beyond the investment horizons of the current investors. Investors' valuation of such securities depends mainly on the price expected to prevail in the market at the investment horizon. Even if the investors have their own respective estimates of the fundamental value, it would be difficult, if not impossible, for them to form an expectation of market price at their own investment horizon through backward induction. Such induction would require them to conjecture not only the dividend expectations of various generations of future investors but also the processes by which each generation carries out such backward induction. For high growth stocks we should expect only a weak link, at best, between the investors' valuation and the fundamental value, as in our short-horizon sessions.

\section{III-2. Experimental Procedures}

The experimental procedures common to all market sessions are as follows. We summarize information about the eleven sessions in Table 1. Each session consisted of some 12 to 17 periods, and each period consisted of three minutes of trading, followed by one or two minutes for paperwork. At the start of the session, each investor received 10 shares and "cash" of 10,000 points. The investors could buy securities if they had cash to pay for them, and sell any shares they had. Short sales were prohibited. Securities and cash were carried

\footnotetext{
${ }^{6}$ One may wonder that the average predicted price (liquidation value) may be a candidate for fundamental value in the short-horizon sessions. This predicted price, however, cannot be considered as the fundamental value because the prediction is, itself, endogenous to the market process that includes the behavior of investors and predictors. No concept of value that deserves the label of fundamental can properly be a function of such behavior because then the label itself becomes superfluous.
} 
over from one trading period to the next. The endowment of securities or cash was not replenished.

Before a session started, each investor drew a Dividend Card, which showed his/her terminal dividend per share. In the long-horizon sessions, this amount would be the actual terminal dividend received by the investor at the end of the last period (period 15). In the short-horizon sessions, the investor would receive this amount at the end of period 30 only if the session were to last for 30 periods. This personal dividend per share was each investor's private information (except that it was common knowledge in Sessions 10 and 11). They were told that the dividend might not be the same across the investors, and that the personal dividends of investors lay within the publicly announced range (see Table 1, column 5).

The session earnings of each investor were equal to the cash balance at the end of the final period's trading, plus the end-of-session payoff, minus the initial cash provided at the beginning of the session. In the long-horizon sessions, the end-of-session payoff was [his or her dividend per share on the Dividend Card $\times$ the number of shares he or she held at the end of the session]. In the short-horizon sessions, the end-of-session payoff was [average predicted price $\times$ the number of shares he or she held at the end of the session] if the session ended before period 30 (this always was the case); it was [his or her dividend per share on the Dividend Card $\times$ the number of shares he or she held at the end of the session] if the session lasted for 30 periods (this was never the case). With the exception of Sessions 8-11, which used relative performance evaluation, the investor's final earnings in all other sessions were converted from points into US dollars at a pre-announced rate, and paid in cash at the end of the experiment.

Trading was by continuous double auction, implemented with the Caplab ${ }^{\mathrm{TM}}$ software. Each investor was free to make bids (proposals to buy shares) and asks (proposals to sell shares) by entering the price and quantity through their mouse and keyboard during trading 
periods. The computer showed the number of shares he or she had, cash balance, market bid and ask price, and the price of the most recent transaction (see Instruction Set 2 for Trading Screen Operation in the Appendix).

All the sessions had predictors as well as investors. After the common instructions and training part of the session, each subject's role (investor or predictor) was determined by lots. The predictors had to estimate the prices at which the investors might trade securities. At the end of each period, they were asked to predict the average stock price of the following period by writing it down on their Price Prediction Sheet. The experimenter gathered this information before starting trading for the period. At the end of each period, the experimenter wrote the predicted price (averaged across all the predictors) on the board for all to see. The predictors' earnings for the period decreased with the magnitude of their prediction errors; they earned [Constant $\mathrm{N}$ - the absolute difference between the prediction and the actual average transaction price] points. If this value was negative, they earned zero points for the period. Constant $\mathrm{N}$ was the same for all the predictors in one session, but differed across sessions (see Table 1 for value of $\mathrm{N}$ ). Their total earnings for all periods were converted from points into US dollars at a pre-announced rate (except in Sessions 8-11 that used relative performance evaluation).

The sequence of activities in a session was as follows: (1) Instruction sets (general instructions, investor instructions, predictor instructions, and trading screen instructions) were distributed and read out aloud. The subjects could ask questions at any time. (2) All the subjects participated in the trial session (2-3 rounds) until they got used to the trading screen operation using Caplab ${ }^{\mathrm{TM}}$. (3) Each subject drew a slip of paper from a bag that determined his or her role. (4) Each investor randomly picked a Dividend Card on which his or her dividend was written. (5) Trading period 1 of the session began and was followed by other periods. 


\section{III-3. Robustness Variations}

As shown in the five sections of Table 2, the main treatment of long and short horizons was supplemented by five variations to examine the robustness of the main treatment to other plausible experimental conditions.

\section{Heterogeneity of terminal dividends:}

In Sessions 6, 10 and 11, the dividends were identical across all the traders. In contrast, in Sessions 1-5 and 7-9, the terminal dividends written on the cards given to the traders were not identical across traders (e.g., 40 for two traders and 75 for two traders in Session 1: see Table 1). This heterogeneous dividend setting creates opportunities to gain from trade and is often adapted in experimental asset market studies (see Sunder [1995] for a review).

\section{Potential inequality between the first and higher-order expectations;}

In Sessions 2, 4, 9, 10 and 11, there existed no gap existed between the actual range of dividends written on individual dividend cards and the maximum dividend range publicly announced to all traders and predictors. For example, in Session 2, three investors were given cards informing them that their own dividend was 70 points, while another three had 130 points as their dividend. It was publicly announced to all subjects that none of the investor dividends lay outside the 70-130 point range. In contrast, in Sessions 1, 3, 5, 6, 7 and 8, a gap existed between the actual range of private dividends and the publicly announced maximum dividend range. For example, as shown in Table 1, dividend cards distributed in Sessions 1 and 8 had a terminal dividend of 40 points for two investors and 75 points for the other two investors. It was publicly announced to all traders and predictors that none of the dividend numbers on the cards given to the investors lay outside the 10-300 point range. The information about this range had some chance of creating a non-zero subjective probability in the minds of investors that the other investors may have dividends as high as 300 points. If the investor's own expectation (first-order expectations) of dividends differs from his 
expectation of others' expectations (second or higher-order expectations), it is possible that even long-horizon investors participate in speculative trading (buy an asset hoping to sell it later to investors with higher private dividends); and such behavior may generate price bubbles $^{7}$. We also check if this occurs in our laboratory.

\section{Common knowledge of predetermined dividends;}

In Sessions 10 and 11, the predetermined dividends written on the trader cards were made common knowledge through a public announcement. In all the other sessions, the predetermined dividends on the cards given to the traders were private knowledge.

\section{Verification of understanding of instructions:}

In Sessions 4-11, the instructions were followed by a written questionnaire and an answer sheet to the questionnaire to help the subjects and the experimenter verify the former's understanding of the instructions and procedures. In addition, Sessions 6-11 included a review of each subject's answers by the experimenter, and an explanation of the relevant part of the procedures in case of any errors in the subject's answers.

\section{Subjects paid by absolute or relative performance:}

In Sessions 1-7, points earned by the subjects were converted into US dollars at a rate announced during the course of the instructions. In Sessions 8-11, the total dollar amount to be paid to the traders (and to the predictors) was announced at the outset. This amount was allocated to individuals in proportion to the number of points earned in the session. ${ }^{8}$

These five robustness variations, as well as the main treatment, are summarized in Table 2. This paper reports on all eleven experimental sessions shown in Tables 1 and 2. The sessions were held at Yale University with undergraduate student subjects in the fall of 2001 through the summer of 2002. A fresh set of subjects were recruited for each of the eleven

\footnotetext{
${ }^{7}$ Biais and Bossaerts' (1998) model shows this possibility.

${ }^{8}$ We adopted relative performance based payment in Sessions 8-11 due to limitations of our budget. In the absolute performance based payment sessions, payment to subjects when a bubble arises could be considerable. For example, in session 2, we paid 138 dollars per subject on average for a 3 hour session. We changed the
} 
sessions, and none had participated in any previous research experiments with stock markets. The sessions lasted 2.5 hours on average.

\section{Experimental Results}

Figures 1-11 show the price and allocation data from the eleven laboratory sessions. Each figure shows the time series of transaction prices (black diamond markers) with the average price for each period written at the top of the chart ${ }^{9}$. The dotted line shows the average predicted price for the period, and the thick solid line indicates the market equilibrium price based on the fundamental value of the shares. The market equilibrium price is the higher of the two dividend values in the heterogeneous dividends sessions (e.g., 150 in Session 3) and the unique dividend value in the homogenous dividends sessions (e.g., 75 in Session 11). The thin solid line shows the upper limit of the publicly announced range of dividends (300 in session 3), which is also, presumably, the upper limit of the investors' and the predictors' second (or higher) order beliefs about dividends.

The small dots plotted against the y-axis on the right hand scales track the allocation of securities relative to the initial endowment $(0$ percent $)$ after each transaction. If all the securities were to be transferred to the investors who had the higher dividend (fundamental value) on their cards, the allocative efficiency would be 100 percent; if all the securities were to be transferred to the investors who had the lower dividend on their cards, the allocative efficiency would be a negative 100 percent.

For example, in Session 1 (short-horizon treatment, Figure 6) the transaction prices (black diamonds) remained in the 80-85 range throughout the session, and stabilized at around 83, about 10 percent above the fundamental value of 75 (thick solid line). These prices were well below the upper limit of the potential second-order beliefs of investors (thin solid line at 300). The average predicted price remained close to 83 throughout (dotted line).

payment policy from absolute to relative for the subsequent short-horizon sessions.

${ }^{9}$ The average prices were calculated by excluding transaction prices that result from order-of-magnitude 
The allocation of securities between the high and the low dividend investors hovered near the initial allocation for the first six periods, and then the higher dividend investors steadily bought all but 1 of the 40 securities by the end of the $12^{\text {th }}$ period.

We organize the data around five results.

Result 1: In the long-horizon sessions, the security prices converge to the equilibrium level derived from the fundamental values of individual investors.

In the long-horizon sessions (Sessions 3, 4, 5, 6, and 7) all the traders knew that there would be 15 periods in the session and that a terminal dividend would be paid at the end of the session. In this zero-discount rate and ample liquidity environment, the fundamental (equilibrium) price for all fifteen periods of these sessions is equal to the highest dividend across traders. Figures 2-5 show that the prices in these markets are determined by this highest dividend, and they converge to the fundamental level. A bubble was observed in Session 3 (Figure 1); it did not, however, reappear in the subsequent sessions (Sessions 4-7) after the experimental instructions were modified to include a questionnaire to test the subject comprehension of the experimental instructions, and additional instruction as necessary. In these four sessions, the prices exhibit a strong tendency to converge to the fundamental value. $^{10}$

This result suggests that long-horizon investors play a crucial role in efficiently pricing securities. Even if prices temporarily deviate from the fundamental values due to speculative or noise trading, long investors' arbitrage tends to bring the prices to their fundamental value. Even in long-horizon sessions, a considerable number of speculative

typographical errors ( 8 transactions in total throughout 11 sessions, see footnotes of the Figures).

${ }^{10}$ We conjecture that in Session 3, a bubble formed because at least some of the subjects did not fully understand the instructions about the structure of the security. In period 4 the price rose to 320 , although the subjects knew that the maximum possible dividend in this market was only 300 . In period 15 , one subject sold shares at a price of 1; we suspect that the seller forgot that the securities earned a liquidating dividend at the end of the last period. In Session 5 (Figure 3), the price dropped below the fundamental value (175) in period 15. The experimenter failed to disable the trading function on the predictors' computers. Although the instructions prohibited predictors from trading, one of the predictors traded anyway, and 14 of the 17 trades in period 15 were sales by this predictor. We confirmed that this predictor's trading had no significant effect on the 
trades took place. In 218 (39 percent) of 559 transactions $^{11}$ in Sessions 3-7, investors bought shares at prices higher than their own terminal dividend, presumably to seek capital gains, not dividends. These speculative trades, however, do not seem to have destabilized the prices. We observe that price deviations from fundamentals are arbitraged away. Even in Session 3 where we experienced a bubble, the price deviations tend to get smaller in the later periods (this is in sharp contrast with the results from short-horizon sessions presented later).

We should add that one of the robustness variations, inequality between the first and higher-order expectations, did not affect our experimental results. Biais and Bossaerts' [1998] model predicts that Keynes' beauty contest bubble arises even when investors have long-term horizons, provided that investors' higher-order beliefs differ from their first-order beliefs. Scheinkman and Xiong [2003] show that when agents have an opportunity to profit from other agents' overvaluation in a market with short-sale constraints, asset prices may exceed their fundamental value. In Sessions 5, 6, and 7, however, where the first and higher-order beliefs might have diverged (also note that our laboratory markets have short-sale constraints), we did not observe any significant gap between the transaction and fundamental prices. ${ }^{12}$

Finally, our result is consistent with Lei, Noussair, and Plott [2001]. Their experimental study attributes the bubbles observed in the laboratory to the subjects' lack of understanding of the structure of the asset, the nature of the task, or the opportunities available to them. In our laboratory, before we started testing the subjects' understanding of the rules, a bubble was observed in Session 3; in the later four sessions where we used questionnaires (Sessions 4 and 5) and verified and corrected any misunderstanding of the

\footnotetext{
convergence pattern to the fundamental value during the first 14 periods of the session.

${ }^{11}$ We exclude 3 transactions that resulted from order-of-magnitude typographical errors in Sessions 4 and 6, and 21 predictor's transactions in Session 5 (see, the previous footnote) as errors from a total of 583 transactions.

${ }^{12}$ It is possible that we did not observe bubbles in Sections 5, 6, and 7 because we did not succeed in our attempt to induce our laboratory subjects to develop divergent first and higher order beliefs about dividends. We asked the subjects "not to assume that other subjects have the same dividends as their own" and announced a range containing all investors' dividends, which was wider than the actual distribution of dividends. We cannot rule out the possibility that this procedure does not necessarily induce divergent first and higher-order beliefs.
} 
rules (Sessions 6 and 7), no bubbles were observed. The lack of understanding of the instructions is a laboratory artifact that must be carefully guarded against in all experiments.

Overall, the data from the long-horizon sessions (Sessions 4, 5, 6 and 7, but not necessarily from Session 3) support Result 1.

Result 2: In the short-horizon sessions, the security prices deviate from the fundamental values.

Figures 6-11 show that, in contrast to the long-horizon treatment of Sessions 3-7, short-horizon Sessions 1, 2, and 8-11 exhibit a strong tendency to generate bubbles. While the dividend numbers seem to have played a role in the determination of prices in the early periods of some of these sessions (e.g., Sessions 1, 8 and 10), as these sessions progressed (see Figures 6-11) the prices often ceased to have any meaningful relationship with the dividends (they were about 10 to 900 percent higher or lower than the fundamental values). Investors did not appear to form their expectations about the liquidation value of the securities from terminal dividend, and backward induct the current value from such expectations. As predicted, the role of terminal dividends in the determination of security prices is minimal at best. Further, the possibility of a gap between the first and the secondorder beliefs in Sessions 1 and 8 does not seem to affect the existence and magnitude of any gaps between prices and terminal dividends. Sessions 2 and 10, in which there was no attempt to induce a divergence between the first and the second (higher) order expectations, resulted in large bubbles.

In all six short-horizon sessions both the levels and the paths of prices are indeterminate. In Session 1 (Figure 6), both the transaction as well as the average predicted prices settled down to about 83 , about 10 percent above the fundamental value, and stayed there throughout. In Session 11 (Figure 11), prices and predictions settled down in the neighborhood of 50, about 33 percent below the fundamental value, and stayed there till the 
end. Both these bubbles, one positive and the other negative, were relatively stable, supported by mutual reinforcement between the transaction prices and the price predictions ${ }^{13}$. In Session 1, there was no reason for any investor to pay a price of 83 for these securities except on the basis of the expectation that he/she will sell them at a similar price in later periods, or get the average predicted price of about 83 at the end of the session. A similar argument applies to Session 11. These stable price paths can be interpreted as evidence of the rational bubbles, considering the zero discount rate in the laboratory. ${ }^{14}$

In Session 2 (Figure 7), prices started out low and increased slowly until an explosive spurt from the middle of period 3 to the middle of period 4. It settled noisily around 900, almost seven times higher than the fundamental price, until the end of the session. The fundamental value (130) hardly played any role in determining the transaction prices. Our conjecture is that the investor \#5 wanted to push the prices higher, and did so until he depleted most of his cash ${ }^{15}$. After this steep rise in prices the predictors started predicting that price, and there was little reason for the prices to return to their fundamental levels. The investors' expectations of high prices in the future seemed to sustain the realization of high prices. This relatively stable price path after Period 5 can also be regarded as a rational bubble. $^{16}$

On the other hand, Sessions 8, 9, and 10 exhibit rising price paths through most of these sessions. Given zero discount rate in the laboratory, these rising paths are not consistent

\footnotetext{
${ }^{13}$ We use the predictors' predictions as proxies for the expectations held by the investors in the experiment. It seems reasonable since the information sets of the predictors and the investors are essentially the same (except for any private dividends). We had different subjects play the two roles to avoid confounding the incentives of the investors and the predictors.

${ }^{14}$ Bubbles with stable prices are also suggested by Ackley (1983). He states, “.... a speculative price-(i.e., a non-equilibrium price) is not always or necessarily a moving price. The price may rest for a considerable period of time at—or fluctuate narrowly around—a level far above (or below) any equilibrium determined by market fundamentals." (p.6)

${ }^{15}$ During period 4, when prices rose shapely, investor \#5 bought 15 shares (out of 30 transactions in this period) and his cash balance went down from 11,966 to 1,353.

${ }^{16}$ In Session 2 (a short-horizon, absolute-performance-payment session), could the predictors have pushed the prices up to help the investors earn more? Since higher price levels are associated with higher variances, raising price levels increases predication errors and reduces the earnings of the predictors. The subjects were recruited independently, and had no knowledge of the game or their role in it, and could not have arranged a scheme of
} 
with rational bubbles prediction. It seems that the actual price increases are followed by increases in price predictions, which in turn help raise the transaction prices. Shiller [2000] argues that this "amplification" mechanism is created by investors' psychological factors and emotions. Our data suggest that the amplification mechanism arises when the investors have short investment horizons and difficulty in backward inducting the value of securities.

In Session 8 (Figure 8), the price grows steadily and by the end of the session it reached above 400, which is about 5 times higher than the fundamentals. In Session 9 (Figure 9), the price settled down around 100 for the first half of the session, which was consistent with a rational bubble. However, it grew sharply during the latter periods. In Session 10 (Figure 10), we observed a large bubble. In this session, the terminal dividend (150) was common knowledge among the investors. However, the dividend seemed to play an anchoring role only during the early periods. In periods $3-5$, the price rose to a level around 200 and continued to rise, even accelerating in periods 9-10, reaching above 1500 in periods 13-14, which was about ten times as high as the fundamental value before falling back about 100 points in period 15 . It is interesting to note the dynamics of transaction and predicted prices. In period 10 the average price prediction was 342 (dotted line) and the actual transactions averages at 390 . In period 11 the predictions rose to 465 , and the transactions rose to 520. In period 12 the predictions and the transactions rose to 815 and 995 respectively. Finally the price prediction rose to 1,500 in period 13 when the actual average price was 1526 . Increases in the transaction and the predicted prices appear to reinforce each other.

In summary, bubbles were observed in all six sessions of the short-horizon treatment where investors should have had difficulty in the backward induction. Instead of being anchored by investors' beliefs about dividends the prices are determined largely by

transfer payments from investors to predictors as an incentive to raise price predictions. 
unanchored anticipations of the future prices. Consequently, the price level and pattern become indeterminate. Our laboratory data provide strong support for Result 2.

Next, we investigate how investors formed their expectations of prices, and what, if any, differences exist between long and short-horizon sessions in this respect.

Result 3: In long-horizon sessions, price expectations are consistent with backward induction; in short-horizon sessions, price expectations are consistent with forward induction.

We examine the price expectation formation process using one backward induction (fundamental) model and two forward induction (adaptive and trend) models

The fundamental model assumes that investors form expectations about the current price by backward inducting from future dividends through a simple statistical adjustment process ( $\alpha$ being the adjustment coefficient):

$$
E_{t}\left(P_{t+1}\right)-P_{t}=\alpha\left(D_{\max }-P_{t}\right)
$$

where $D_{\max }$, the largest (across investors) terminal dividend value in the market, is the fundamental value of the security. Except in Sessions 10 and 11, $D_{\max }$ is not announced to the investors and predictors; the dividend range is publicly announced but each investor's dividend is private information. It is possible that subjects rationally predict $D_{\max }$ by observing transaction prices if the market is efficient in the sense that prices reflect investors' private information. This strong form efficiency was actually observed in simple repeated experimental asset markets [Forsythe, Palfrey, and Plott 1982, Plott and Sunder 1982]. As our laboratory markets are simple enough (the security pays only a terminal dividend) and repeated for some 12-17 periods under unchanging conditions, the subjects may have a rational prediction on $D_{\max }$ and utilize it in forming their expectations of prices (5).

This fundamental (backward induction) model is compared with two forward induction models. One is the first-order adaptive model:

$$
E_{t}\left(P_{t+1}\right)=E_{t-1}\left(P_{t}\right)+\beta^{\prime}\left(P_{t}-E_{t-1}\left(P_{t}\right)\right)
$$


The expectation at $t$ is formed by adding a fraction $\left(\beta^{\prime}\right)$ of the most recent expectation error to the most recent expectation. To compare it with the other models, we rewrite it as

$$
E_{t}\left(P_{t+1}\right)-P_{t}=\beta\left(E_{t-1}\left(P_{t}\right)-P_{t}\right)
$$

The other forward induction process is a simple trend model:

$$
E_{t}\left(P_{t+1}\right)-P_{t}=\gamma\left(P_{t}-P_{t-1}\right)
$$

This model is often called an extrapolative expectation model. The expectation at $t$ is formed by adding a fraction $(\gamma)$ of the most recent price change $\left(P_{t}-P_{t-1}\right)$ to the most recent observed price $\left(P_{t}\right)$. When $\gamma>0$, recent price increases cause investors to expect further price increases in the future.

Finally, we consider a more general specification for expectation formation that include the fundamental, adaptive, and trend factors simultaneously:

$$
E_{t}\left(P_{t+1}\right)-P_{t}=\alpha\left(D_{\max }-P_{t}\right)+\beta\left(E_{t-1}\left(P_{t}\right)-P_{t}\right)+\gamma\left(P_{t}-P_{t-1}\right)
$$

This combined model allows for the possibility that investors use some combinations of the three simple processes to form their expectations. Estimates of multiple regressions (9) can also help us detect any biases in the estimates of simple regressions, (5), (7), and (8), due to the omitted variables problem.

We estimated regression equations (5), (7), (8), and (9) including constant terms on two samples, one had pooled the data from all five long-horizon sessions and the other had pooled the data from all six short-horizon sessions. Price predictions submitted by the predictors were used as measures of price expectations. Our null hypothesis is that expectations are static, $E_{t}\left(P_{t+1}\right)=P_{t}: \alpha, \beta$, and $\gamma$ are equal to zero in (5), (7), and (8), respectively, and all three parameters are zero in $(9) .{ }^{17}$

\footnotetext{
${ }^{17}$ To cope with heteroskedasticity, we used White's (1980) heteroskedastic-consistent standard error to test the significance of the coefficients. Furthermore, we also run weighted least squares regressions and found that the inferences given below remained unchanged.
} 
Two panels of Table 3 show the regression results for the long and short-horizon samples respectively. In the long-horizon sessions ${ }^{18}$, the data are more consistent with the backward induction (fundamental) model than with either of the two forward induction (adaptive and trend) models. While the coefficient of $\left(D_{\max }-P_{t}\right)$ is significantly positive in the fundamental model (5), neither coefficient of $\left(E_{t-1}\left(P_{t}\right)-P_{t-1}\right)$ nor $\left(P_{t}-P_{t-1}\right)$ is significant in the adaptive model (7) and trend model (8). In the estimation result of the combined model (9), only the fundamental factor $\left(D_{\max }-P_{t}\right)$ is significant. These results suggest that in longhorizon sessions, the fundamental value of the security not only determines transaction prices but also critically affect the price expectations. The existence of long-horizon traders plays a role in informing market participants of the fundamental values and, at the same time, seems to enable them to expect that future price will converge to the fundamentals. Under such circumstances, investors' speculation caused by future price expectation should have a stabilizing effect on market prices. We conjecture that this mechanism actually worked in our long-horizon sessions; prices converged to the fundamental value even though about 40 percent of the trades can be attributed to speculative motives because they represented purchases at a price above personal dividends.

On the contrary, Panel B of Table 3 shows that in short-horizon sessions, the forward induction models are supported over the backward induction model. First, while the adaptive factor $\left(E_{t-1}\left(P_{t}\right)-P_{t-1}\right)$ is insignificant in the simple regression (7), it is significant at 1 percent level in the more general specification (9). Second, the trend factor $\left(P_{t}-P_{t-1}\right)$ is significantly positive at a 5 percent level in the simple regression (8) and at a 1 percent level in the combined regression (9). On the other hand, the fundamental factor, $\left(D_{\max }-P_{t}\right)$, is not significant in either of the two specifications ((5) or (9)).

\footnotetext{
${ }^{18}$ In period 3 of Session 4, one predictor submitted an abnormally high price prediction (600), after observing an order-of-magnitude typographical error in a trading price in period 2 . We regard this expectation data as a noise and exclude from the sample. Inclusion of this datum does not change our results.
} 
These results indicate that in short-horizon sessions price expectations are formed by forward induction from current or past transaction prices. Extant field and experimental studies generally support an adaptive expectation model, but not a trend (extrapolative) model [Frankel and Froot 1987, Williams 1987]. In contrast, our data indicate that the trend factor has a considerable effect on future price expectations in short-horizon sessions - a price rise of 1 raising the expectation of next period price by 0.47 . In estimates from the combined model (9), this effect is larger at 0.83 (see, Panel B in Table 3). Given the random noise in transaction prices, formation of expectations on the basis of the most recent trend holds considerable potential to destabilize prices. A change in price for any reason changes investors' expectation of future prices in the same direction, and it becomes rational to bid the prices up or down in the same direction. The model estimates suggest that such an amplification mechanism occurred in Sessions 8-10.

Result 4: The allocative efficiency is high in the long-horizon sessions; it is unpredictable in the short-horizon sessions.

The allocative efficiency (the percent of securities transferred toward the fundamental value equilibrium allocation) for Sessions 1-5 and 7-9 is plotted in Figures 1-3 and 5-9 with small dots on the right hand scale ${ }^{19}$. During the three long-horizon sessions (Sessions 4, 5 and 7) almost all the securities ended up in the hands of the high fundamental value traders, and the allocative efficiency approached 100 percent at the end of each session. In Session 3, the efficiency hovered around zero during the bubble phase (Periods 1-9). The bubble collapsed in the last five periods as the securities were transferred to the high-dividend investors $^{20}$.

\footnotetext{
${ }^{19}$ In sessions 6 (Figure 4), 10 (Figure 10) and 11 (Figure 11), all investors had identical dividends and the allocative efficiency was undefined.

${ }^{20}$ The efficiency dropped just before the end of Session 3. After the session ended, a high-dividend trader who had accumulated a large number of securities told us that in period 15 he forgot that there was a terminal dividend, panicked, and sold off many securities at a price of 1 .
} 
The bubble economies of the short-horizon Sessions 8 and 9 had negative efficiencies (the securities were transferred to low-dividend investors), and Session 2 had an efficiency of only 20 percent. When the dividends are replaced by endogenously determined predicted prices, such as the liquidation payoff, there is no reason to expect either high or low efficiencies in the market. Every trader would get the same liquidation payoff from holding the security, and the market exerts little pressure to make the allocation of resources more efficient as defined by the ultimate (period 30) dividends. ${ }^{21}$

The uncertain allocative efficiency of bubble-prone markets is an argument for public policies aimed at discouraging the formation of price bubbles. Bubbles also have significant distributive consequences in the form of increasing the dispersion of wealth among agents.

Result 5: The cross-sectional dispersion of investor wealth increases with the size of bubbles.

The cross-sectional distribution of relative profits of individual traders (= individual trader's profit in points / the fundamental value of the initial endowment of 10 shares - the cross-sectional average of this ratio) for each of the eleven sessions are shown in Figure 12. Each triangle marker represents one trader's relative profit. The standard deviations of the relative profits are shown in parentheses under the session numbers.

Of the five long-horizon sessions, only Session 3, which had a large price bubble, shows a significant cross-sectional dispersion of profits (the standard deviation of the relative profits is 3.88). The dispersion in all other sessions is close to zero. Of the six short-horizon sessions, 1 and 11 had small but stable bubbles, and the dispersion of relative profits in these sessions is close to zero. In the other four sessions we observed large price bubbles, all of

\footnotetext{
${ }^{21}$ However, in Session 1, the efficiency rose to almost 100 percent. Since the investors could be reasonably sure that they would get the average predicted price that hovered around 83 through almost the entire session, there was no pressure for the securities to be transferred to the higher-dividend investors. In fact, 39 of the 40 securities were held by one of the two high-dividend investors at the end of Period 12. One low-dividend investor held one security, while one high-dividend and one low-dividend investor held no securities. It is therefore plausible that the transfer of securities to one high-dividend investor could have been the outcome of idiosyncratic trading strategies of the investors, and the securities could have just as easily ended up in the hands of any of the other three investors.
} 
them show large dispersion of individual profits. The data suggest that the dispersion of wealth increases with the magnitude of the price bubble.

\section{Discussion and Concluding Remarks}

In the eleven laboratory sessions of this experiment, we observe that when investor decision horizons are short (relative to maturity of the security) and they face a difficult backward induction task, the security prices tend to deviate from fundamentals to form bubbles. In these circumstances, prices lose their dividend anchors and become indeterminate. While some price paths are consistent with rational bubbles, others exhibit positive feedback loops. Market participants tend to form their expectations of future prices through forward induction, using first-order adaptive or trend processes. These results are robust to several variations in experimental conditions.

Our laboratory findings suggest several insights into the stock market environments where bubbles are likely to occur. First, investors' time horizons are critical to asset pricing. The frequency and impact of the failure of backward induction in a market is greater when it is populated or dominated by short-term traders (e.g., day traders); security prices in such markets are more likely to deviate from the fundamental value. In contrast, the existence of long-term investors is crucial for stabilizing market prices near the fundamentals, not only through their arbitrage activity but also through their expectations which are anchored to their estimates of future dividends.

Second, securities with longer maturities — generally, longer duration securities ${ }^{22}$ - are more susceptible to bubbles. As the duration of a security increases, investors receive smaller proportion of its value in the form of dividends within their investment horizons; and a greater part of their value depends on the expectations of capital gains, which in turn depends on higher-order expectations. Such higher order expectations might be unstable because of

\footnotetext{
${ }^{22}$ Duration is the first derivative of the present value of a security with respect to the discount rate, or the weighted average time of cash flows associated with the security.
} 
the possibility of the failure of backward induction. Therefore the prices of securities with longer durations are more likely to deviate from the fundamentals. This effect of firm's dividend policy on the volatility and the level of its stock price can be added to the tax, agency, and signaling theory challenges to the Miller and Modigliani’s [1961] dividend irrelevance proposition.

Third, bubbles are more likely to occur when the future dividends are more uncertain. In such cases, it is difficult for the investors to conjecture what others think (and what others think about what others think) about the future prospects of dividends. It becomes more likely for the investors to fail to backward induct, and for the prices to be unhinged from their dividend anchors.

These implications - the influence of investment horizon, maturity and duration, and uncertainty on the likelihood and severity of bubbles - can be tested by using data from the field, as well as by conducting further laboratory experiments. They appear to be consistent with casual observations of stock market behavior. Historically, price bubbles have often been attributed to securities with longer maturity or duration and greater uncertainty about the fundamentals, such as high-growth and new technology stocks [see Blanchard and Watson 1982 and Ackley 1983]. The so-called "dotcom" bubble is a recent example. It seemed that Internet stocks lost their dividend anchors and suffered from price indeterminacies, as did our laboratory stocks in short-term horizon sessions.

Our experimental result also shows that the allocative efficiency of markets is high in long-term horizon sessions and becomes indeterminate in short-term horizon sessions. Since the efficient allocation of capital, not gambling, is supposed to be the social function of security markets, it is understandable that policy makers view bubbles to be undesirable. Furthermore, the evidence on the tendency of bubbles to increase the cross-sectional dispersion of wealth serves as another reason for policy intervention in markets. 
In recent decades, many researchers have presented evidence against the market efficiency. Shiller [1981] concludes that, given the fundamentals, security prices are too volatile. French and Roll [1986] observed that the volatility is greater when the markets are open, and inferred that the market trading itself seems to create volatility. This inference is consistent with forward induction. Recent behavioral finance research argues that emotion and psychological factors have considerable effect on stock prices [Shiller 2000], and that momentum trading strategies sometimes work [Narasimhan and Titman 2001, Goetzmann and Massa, 2004]. Our experimental results imply that such phenomena are more likely to be observed when the market is mainly populated by short-term investors who, facing difficulty of the backward induction, resort to forward induction.

\section{References}

Ackley, G., "Commodities and Capital: Prices and Quantities," American Economic Review, LLXIII, 1983, 1--16.

Allen, F., S. and G. Gorton, “Churning Bubbles,” Review of Economic Studies, LX, 1993, 3-836.

Allen, F., S. Morris, and H. S. Shin, "Beauty Contests, Bubbles and Iterated Expectations in Asset Markets,” working paper, 2002, Yale University.

Allen, F., S. Morris, and A. Postlewaite, "Finite Bubbles with Short Sale Constraints and Asymmetric Information,” Journal of Economic Theory, LXI, 1993, 206--229.

Blanchard, O., and M. W. Watson, "Bubbles, Rational Expectations and Financial Markets," in Crises in the Economic and Financial System, ed. by P. Wechtel, Lexington Books, Lanham, MD, 1982. 
Biais, B., and P. Bossaerts, , “Asset Prices and Trading Volume in a Beauty Contest,” Review of Economic Studies, LXV, 1998, 307--340.

DeLong, J. B., A. Shleifer, L. Summers, and R. Waldmann, "Noise Trader Risk in Financial Markets," Journal of Political Economy, LXVIII, 1990a, 703--738.

DeLong, J. B., A. Shleifer, L. Summers, and R. Waldmann,. "Positive Feedback Investment Strategies and Destabilizing Rational Speculation,” Journal of Finance, XLV, 1990b, 375--395.

Dow, J. and G. Gorton, “Arbitrage Chains,” Journal of Finance, XLIX, 1994, 819--849.

Fama, E. F., Efficient Capital Markets: II, Journal of Finance XL, 1991,1575--1617.

Frankel, J. A., and K. A. Froot, "Using Survey Data to test Standard Propositions Regarding Exchange Rate Expectations,” American Economic Review, LXXVII, 1987,133--153.

French, K., and R. Roll, "Stock Market Variances: the Arrival of Information and the Reaction of Traders," Journal of Financial Economics, XVII, 1986, 5--26.

Froot, K. A., D. S. Scharfstein, and J. C. Stein, "Herd on the Street: Informational Inefficiencies in a Market with Short-Term Speculation,” Journal of Finance, XLVII, 1992, 1461--1484.

Goetzmann, W. and Massimo Massa.. "Daily Momentum and Contrarian Behavior of Index Fund Investors,” Journal of Financial and Quantitative Analysis, 2004 ,(forthcoming).

Lei, V., C. N. Noussair, and C. R. Plott, "Nonspeculative Bubbles in Experimental Asset Markets: Lack of Common Knowledge of Rationality vs. Actual Irrationality," Econometrica, LXIX, 2001, 831--859.

LeRoy. S. F., "Rational Exuberance," mimeo, 2003.

Miller, M., and F. Modigliani, "Dividend Policy, Growth and the Valuation of Shares," Journal of Business, XXXIV, 1961,411--433. 
Narasimhan, Jagadeesh, and Sheridan Titman.. "Momentum,” University of Illinois Working Paper, 2001.

Scheinkman, Jose and Wei Xiong, “Overcnfidence and Speculative Bubbles," Journal of Political Economy, CXXI, 2003, 1183-1219.

Shiller, R. J., "Do Stock Prices Move Too Much to Be Justified by Subsequent Changes in Dividends," American Economic Review, LXXI, 1981,421--436.

Shiller, R. J., Irrational Exuberance, 2000,Princeton University Press, Princeton, NJ.

Smith, V. L., G. L. Suchanek, and A. W. Williams, "Bubbles, Crashes, and Endogenous Expectations in Experimental Spot Asset Markets.” Econometrica, LVI, 1988, $1119--1151$

Stiglitz, J. E., “Symposium on Bubbles," Journal of Economic Perspectives, IV, 1990, 13-18 .

Sunder, S., "Experimental Asset Markets: A Survey," in Handbook of Experimental Economics, 1995, eds. by Kagel, J. H. and A. E. Roth, Princeton University Press. Princeton, NJ.

Tirole, J., "On the Possibility of Speculation under Rational Expectations," Econometrica, L, 1982, 1163--1181.

Tirole, J., “Asset Bubbles and Overlapping Generations,” Econometrica, LIII, 1985, 1499$-1528$.

White, H., , "Heteroskedasticity-consistent Covariance Matrix Estimator and a Direct Test for Heteroskedasticity,” Econometrica, XLVIII, 1980, 817--838.

Williams, A. W., "The Formation of Price Forecasts in Experimental Markets," Journal of Money, Credit, and Banking, XIX, 1987,1--18. 


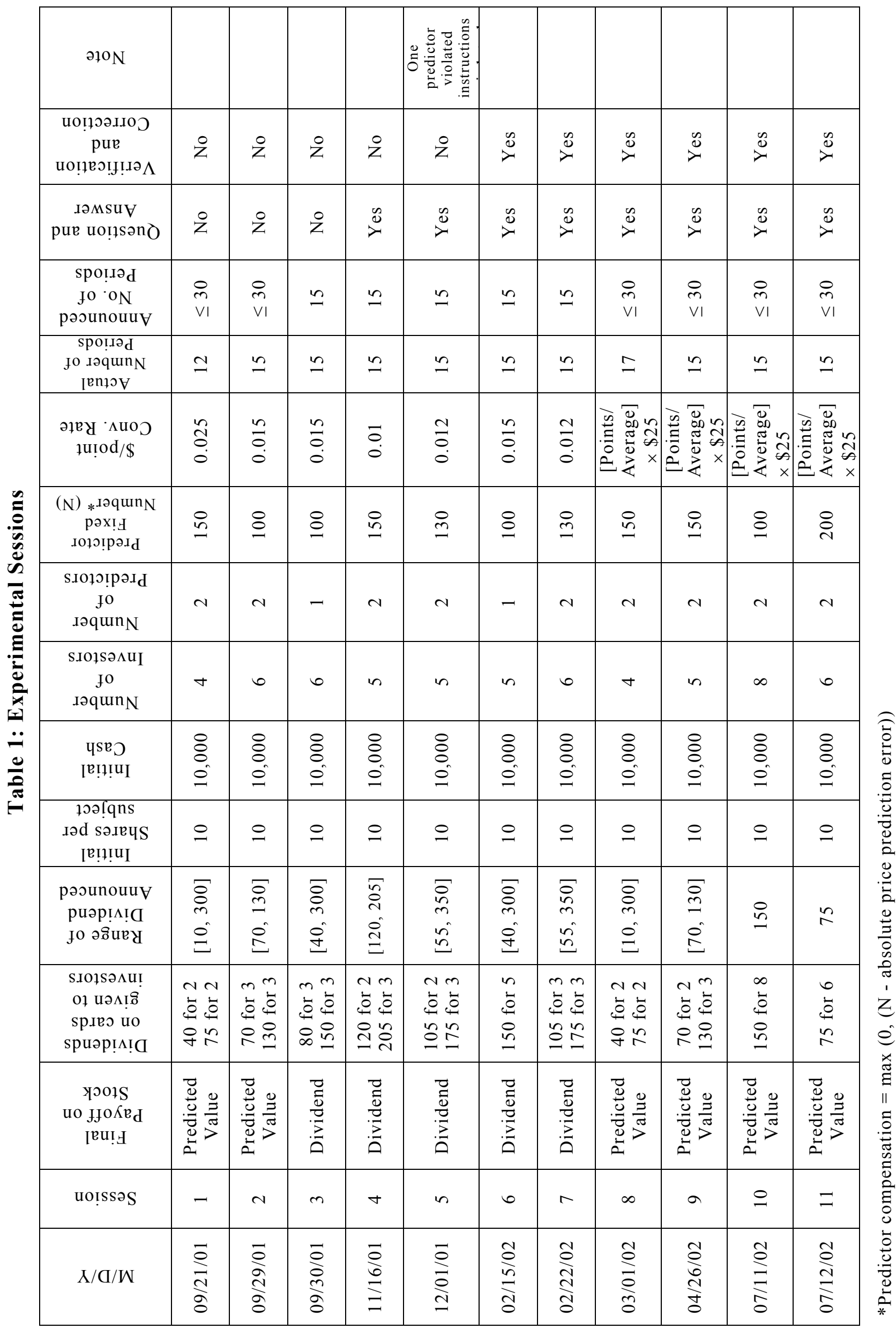


Table 2: Experimental Design

\begin{tabular}{|c|c|c|c|}
\hline & & \multicolumn{2}{|c|}{ Main Treatment: Investment Horizon } \\
\hline Robustness Variations & & Long-Horizon Session & Short-Horizon Session \\
\hline \multirow{2}{*}{$\begin{array}{l}\text { Subsidiary Treatment 1: } \\
\text { Heterogeneity of } \\
\text { pre-determined dividends }\end{array}$} & $\begin{array}{l}\text { Identical pre-written } \\
\text { dividends }\end{array}$ & Session 6 & Sessions 10 and 11 \\
\hline & $\begin{array}{l}\text { Non-identical pre- } \\
\text { written dividends }\end{array}$ & Sessions $3,4,5$, and 7 & Sessions $1,2,8$, and 9 \\
\hline \multirow{2}{*}{$\begin{array}{l}\text { Subsidiary Treatment 2: } \\
\text { Potential inequality of the } \\
\text { first and higher order } \\
\text { beliefs about dividends }\end{array}$} & $\begin{array}{l}\text { Equality between first } \\
\text { and higher order beliefs }\end{array}$ & Session 4 & Sessions $2,9,10$, and 11 \\
\hline & $\begin{array}{l}\text { Potential for a gap } \\
\text { between first and higher } \\
\text { order beliefs }\end{array}$ & Sessions $3,5,6$, and 7 & Sessions 1,8 \\
\hline \multirow{2}{*}{$\begin{array}{l}\text { Subsidiary Treatment 3: } \\
\text { Common Knowledge of } \\
\text { pre-determined dividends }\end{array}$} & $\begin{array}{l}\text { Dividends common } \\
\text { knowledge }\end{array}$ & & Sessions 10 and 11 \\
\hline & $\begin{array}{l}\text { Dividends not common } \\
\text { knowledge }\end{array}$ & Sessions $3,4,5,6$, and 7 & Sessions $1,2,8$, and 9 \\
\hline \multirow{3}{*}{$\begin{array}{l}\text { Subsidiary Treatment 4: } \\
\text { Verification of proper } \\
\text { understanding of the } \\
\text { instructions }\end{array}$} & $\begin{array}{l}\text { Questionnaire, answer, } \\
\text { No verification and } \\
\text { correction }\end{array}$ & Sessions 4 and 5 & \\
\hline & $\begin{array}{l}\text { Questionnaire, answer, } \\
\text { verification and } \\
\text { correction }\end{array}$ & Sessions 6 and 7 & Sessions $8,9,10,11$ \\
\hline & $\begin{array}{l}\text { No questionnaire, } \\
\text { answer, verification and } \\
\text { correction }\end{array}$ & Session 3 & Sessions 1 , and 2 \\
\hline \multirow{2}{*}{$\begin{array}{l}\text { Subsidiary Treatment 5: } \\
\text { Subjects paid by absolute } \\
\text { or relative performance }\end{array}$} & $\begin{array}{l}\text { Payoff based on absolute } \\
\text { performance }\end{array}$ & Sessions $3,4,5,6$ and 7 & Sessions 1 and 2 \\
\hline & $\begin{array}{l}\text { Payoff based on relative } \\
\text { performance }\end{array}$ & & Sessions $8,9,10$, and 11 \\
\hline
\end{tabular}




\section{Table 3: Price Expectation Model Estimates}

Panel A: Long-Horizon Sessions

\begin{tabular}{|c|c|c|c|c|c|c|}
\hline Model & Const. & $D_{\max }-P_{t}$ & $E_{t-1}\left(P_{t}\right)-P_{t}$ & $P_{t}-P_{\mathrm{t}-1}$ & $\bar{R}^{2}$ & $\mathbf{N}$ \\
\hline $\begin{array}{c}\text { Fundamental } \\
(5)\end{array}$ & $\begin{array}{c}5.705 \\
(5.386)\end{array}$ & $\begin{array}{c}0.261 * * \\
(0.098)\end{array}$ & & & 0.085 & 102 \\
\hline $\begin{array}{c}\text { Adaptive } \\
(7)\end{array}$ & $\begin{array}{c}4.863 \\
(6.075)\end{array}$ & & $\begin{array}{c}0.428 \\
(0.396)\end{array}$ & & 0.045 & 102 \\
\hline $\begin{array}{c}\text { Trend } \\
(8)\end{array}$ & $\begin{array}{c}3.318 \\
(5.643)\end{array}$ & & & $\begin{array}{c}-0.189 \\
(0.333)\end{array}$ & 0.002 & 102 \\
\hline $\begin{array}{c}\text { Combined } \\
(9)\end{array}$ & $\begin{array}{c}6.646 \\
(6.321)\end{array}$ & $\begin{array}{c}0.200 * * \\
(0.074)\end{array}$ & $\begin{array}{c}0.443 \\
(0.235)\end{array}$ & $\begin{array}{c}0.178 \\
(0.274)\end{array}$ & 0.090 & 102 \\
\hline
\end{tabular}

Panel B: Short-Horizon Sessions

\begin{tabular}{|c|c|c|c|c|c|c|}
\hline Model & Const. & $D_{\max }-P_{t}$ & $E_{t-1}\left(P_{t}\right)-P_{t}$ & $P_{t}-P_{\mathrm{t}-1}$ & $\bar{R}^{2}$ & $\mathbf{N}$ \\
\hline $\begin{array}{c}\text { Fundamental } \\
(5)\end{array}$ & $\begin{array}{c}3.543 \\
(4.593)\end{array}$ & $\begin{array}{c}-0.077 \\
(0.042)\end{array}$ & & & 0.092 & 166 \\
\hline $\begin{array}{c}\text { Adaptive } \\
(7)\end{array}$ & $\begin{array}{c}19.851 * * \\
(6.869)\end{array}$ & & $\begin{array}{c}-0.113 \\
(0.149)\end{array}$ & & 0.010 & 166 \\
\hline $\begin{array}{c}\text { Trend } \\
(8)\end{array}$ & $\begin{array}{c}5.809 \\
(4.411)\end{array}$ & & & $\begin{array}{c}0.467 * \\
(0.196)\end{array}$ & 0.349 & 166 \\
\hline $\begin{array}{c}\text { Combined } \\
(9)\end{array}$ & $\begin{array}{c}4.808 \\
(3.244)\end{array}$ & $\begin{array}{c}0.027 \\
(0.027)\end{array}$ & $\begin{array}{c}0.543 * * \\
(0.179)\end{array}$ & $\begin{array}{c}0.829 * * \\
(0.164)\end{array}$ & 0.506 & 166 \\
\hline
\end{tabular}

** and * indicate that the coefficient is significantly different from zero at the $1 \%$ and $5 \%$ level at twotailed test, respectively. Figures in parentheses are White's (1980) heteroskedastic-consistent standard errors. 

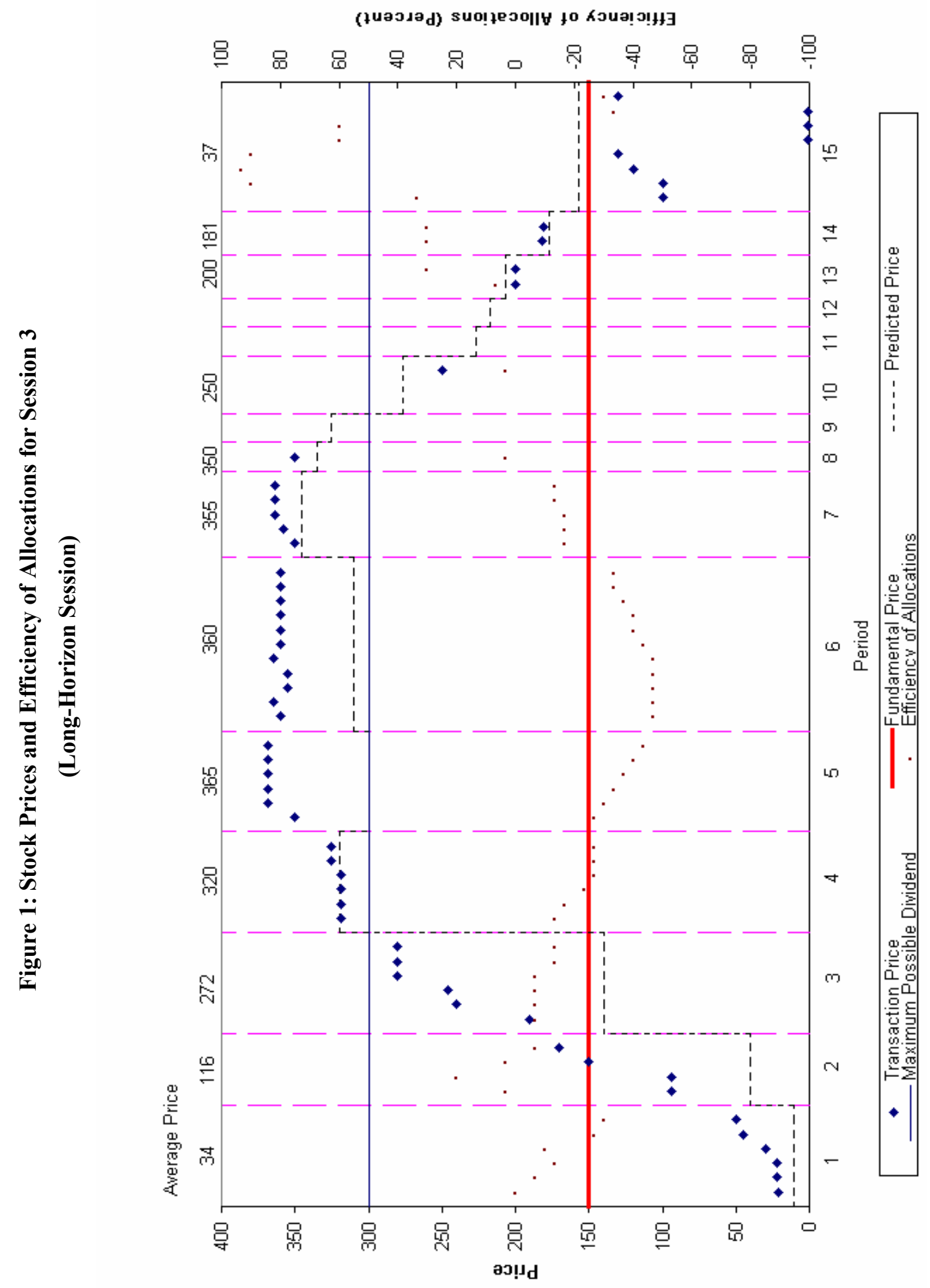

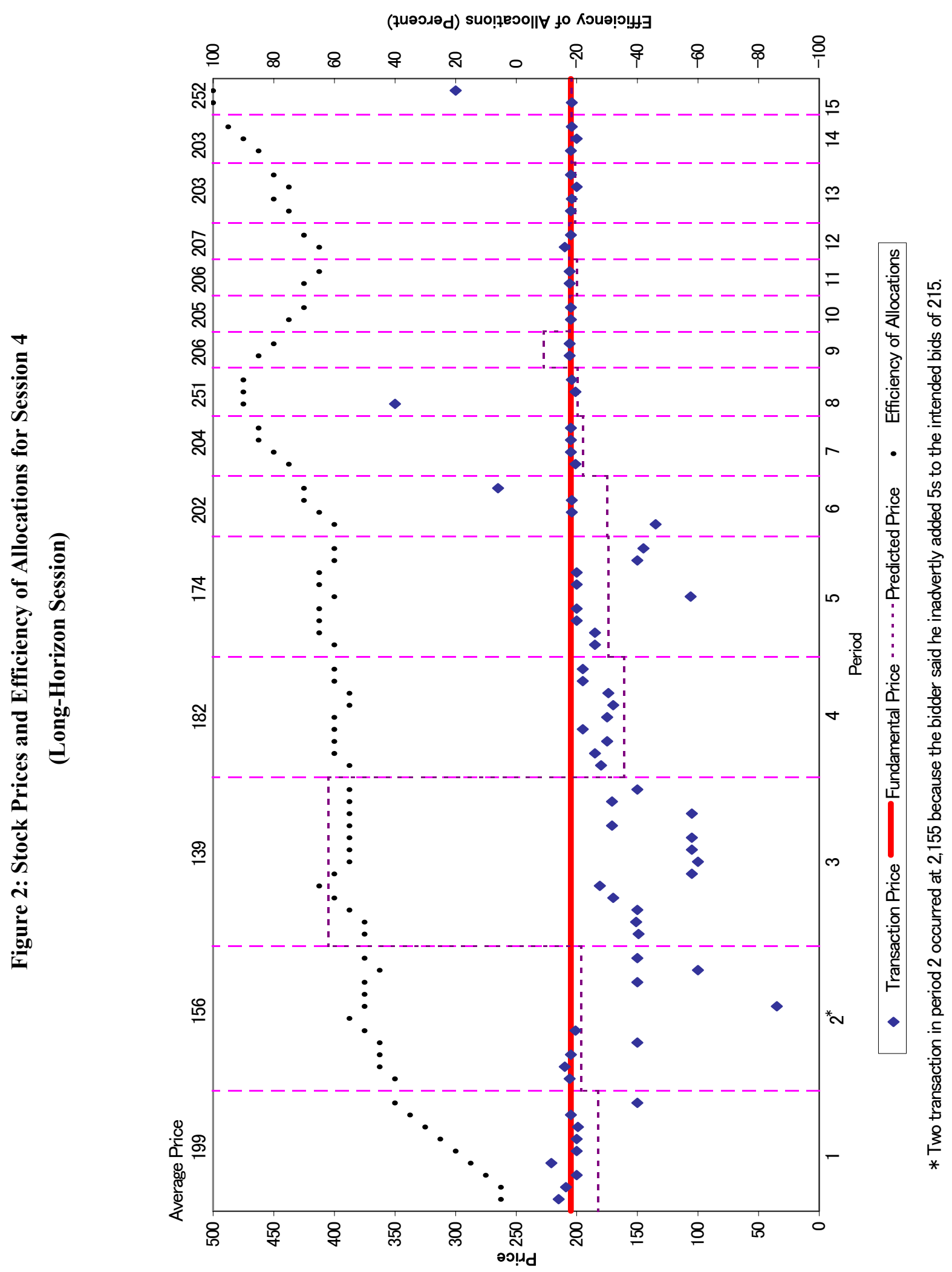


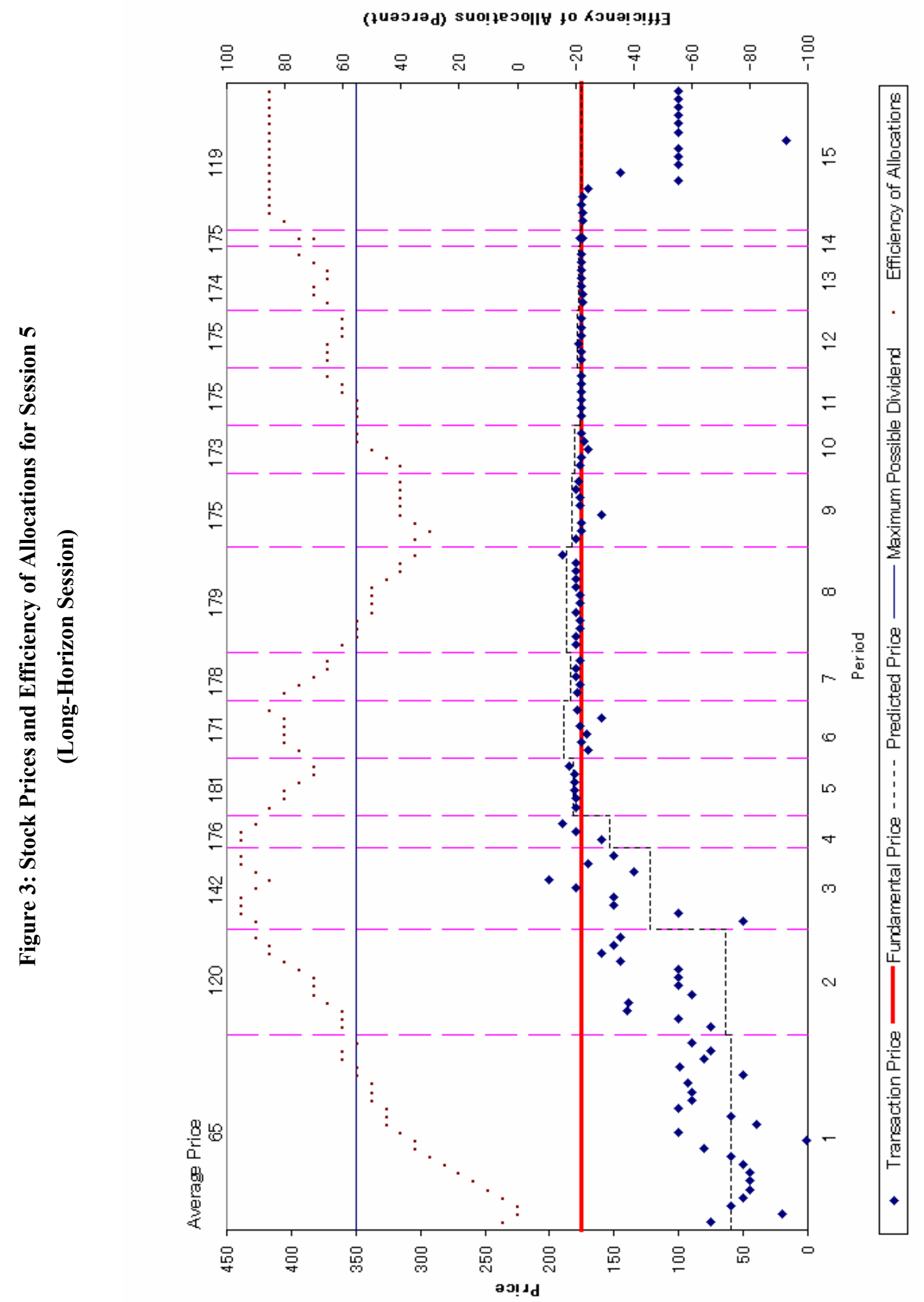




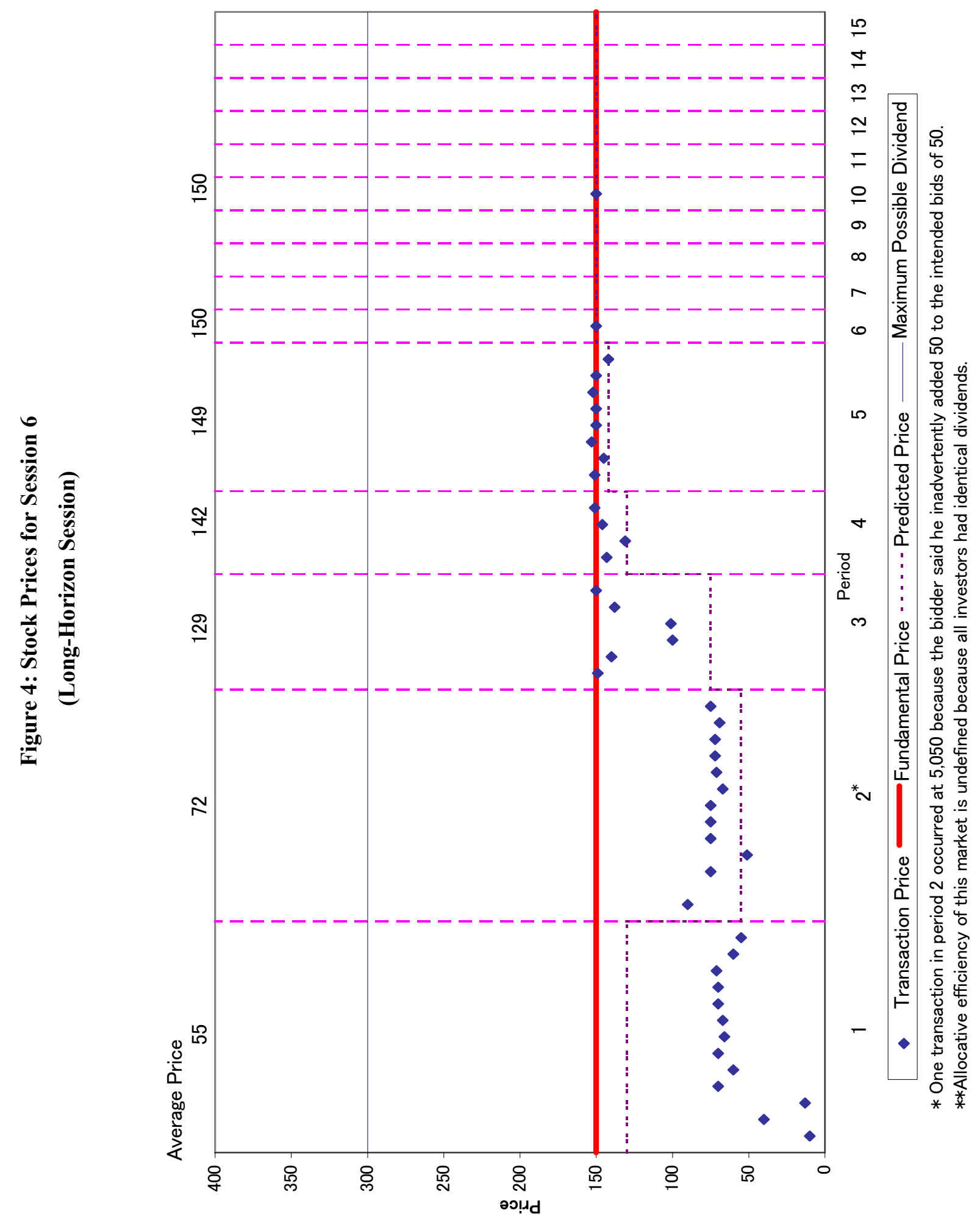




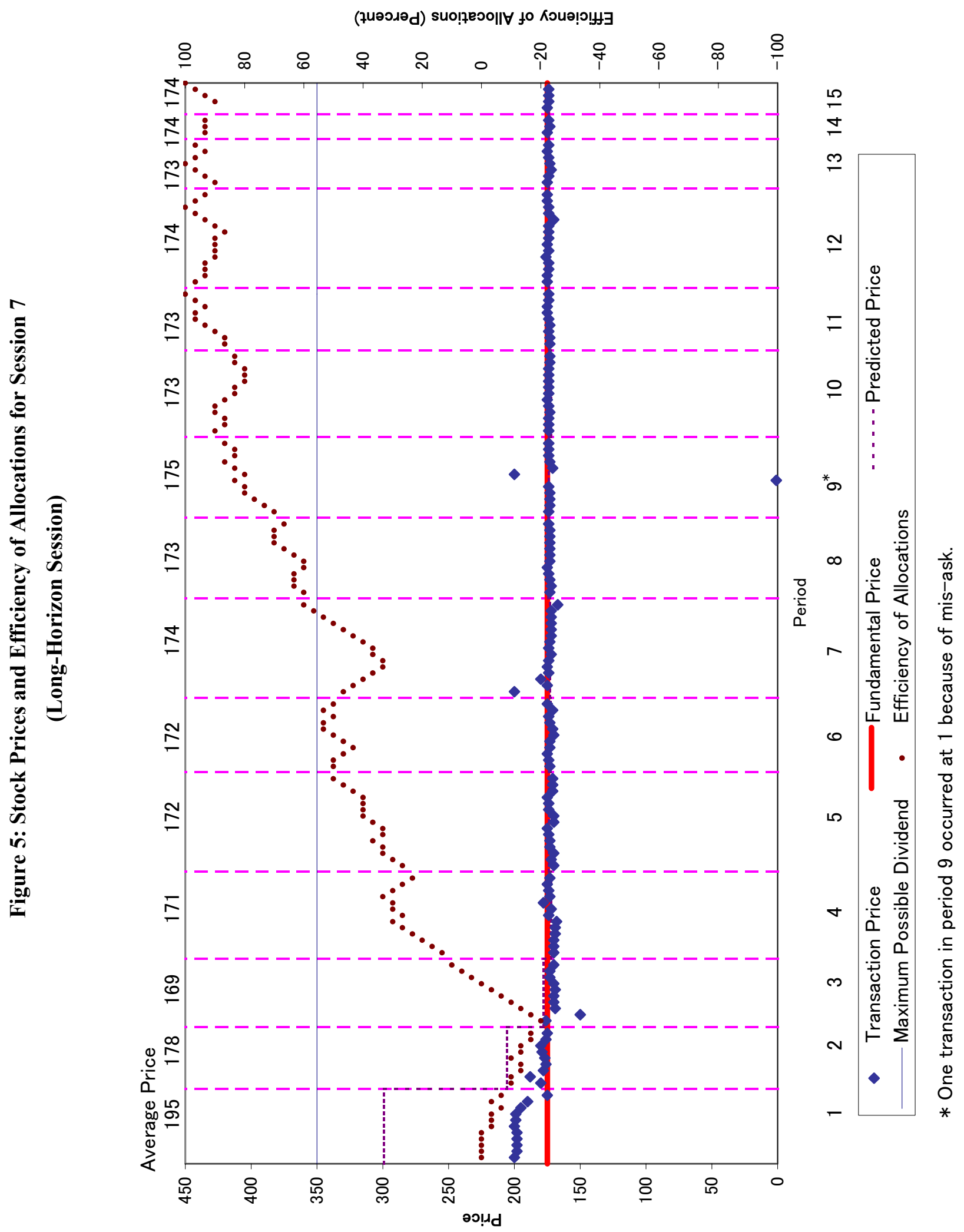




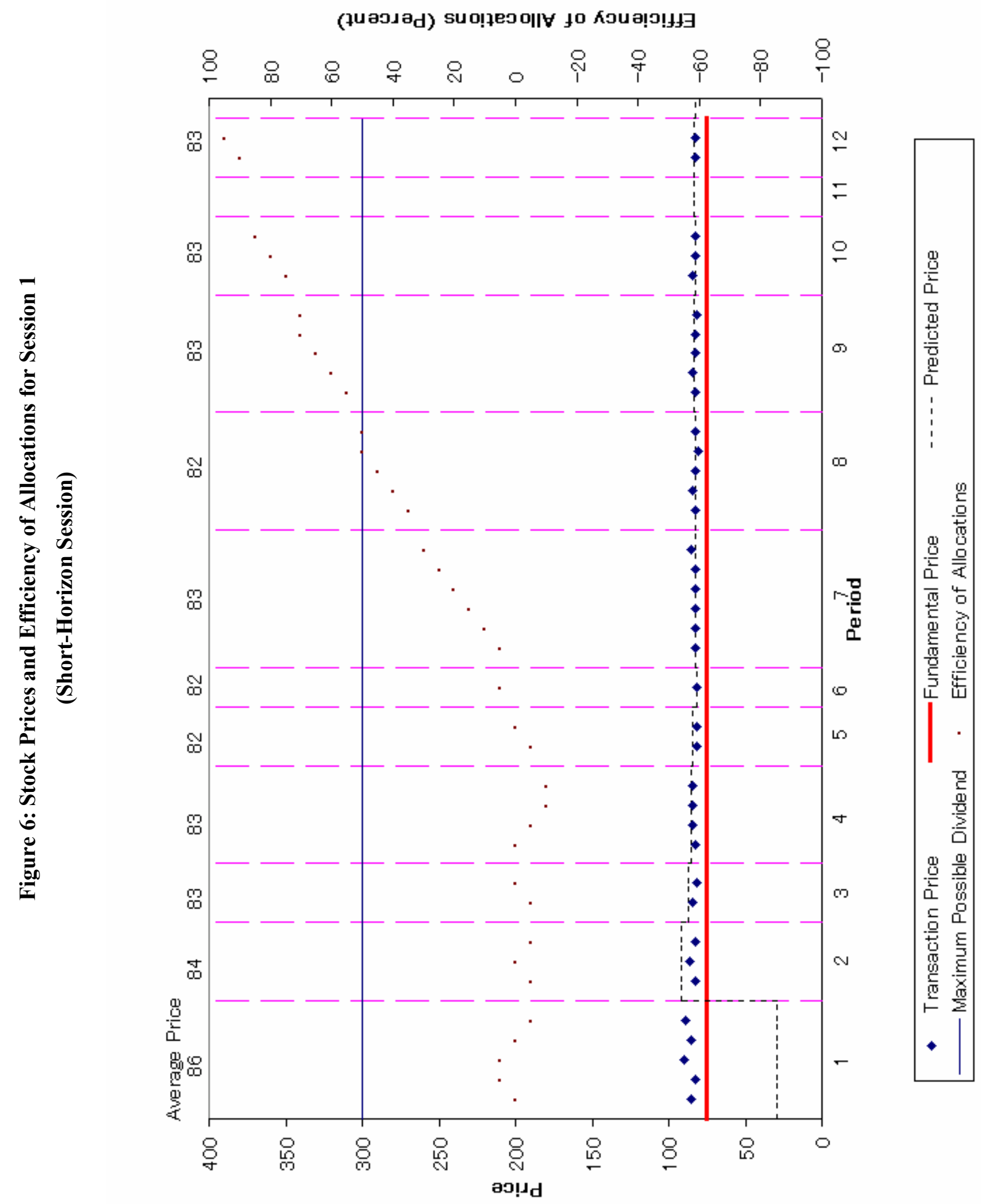




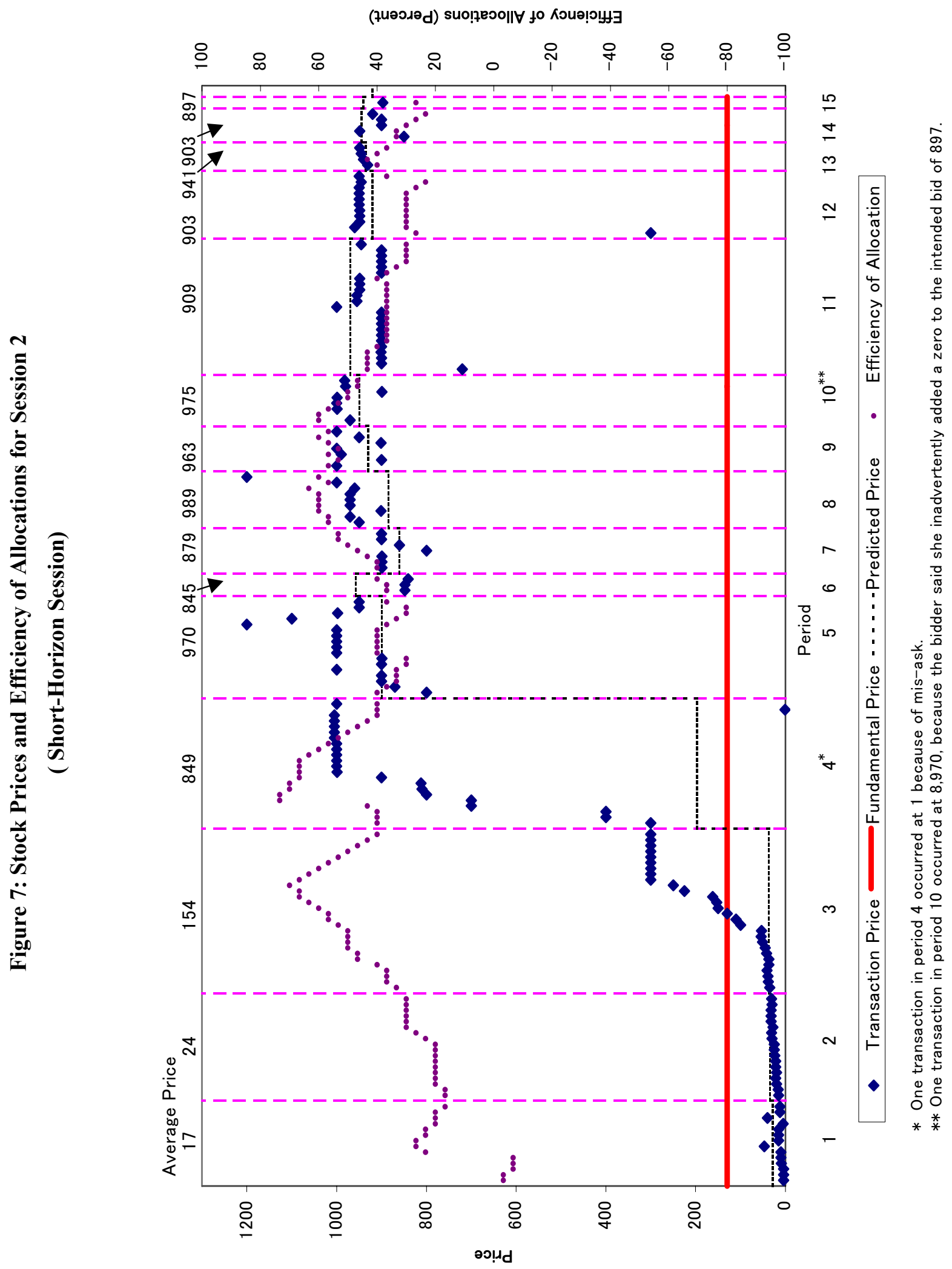




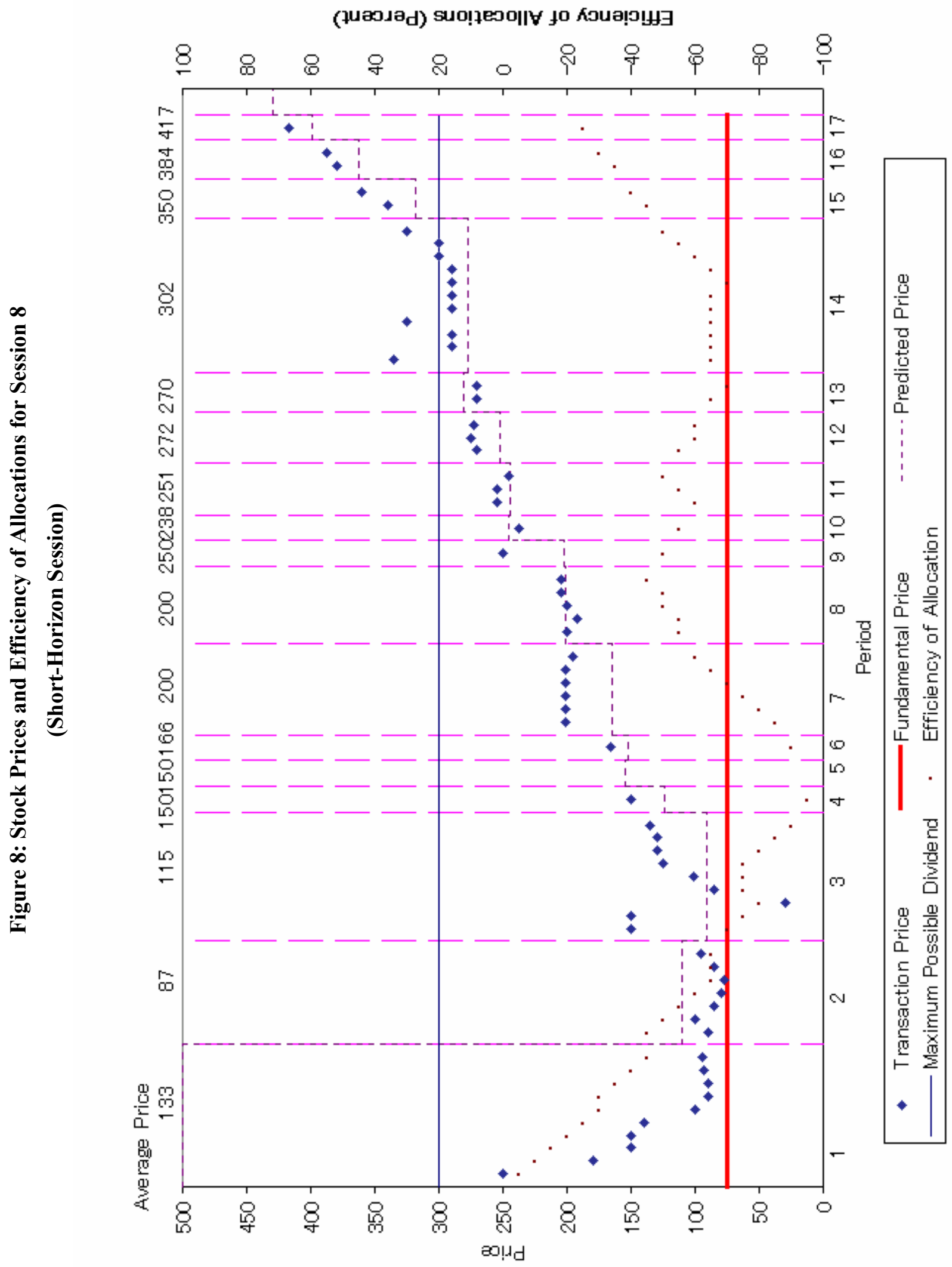




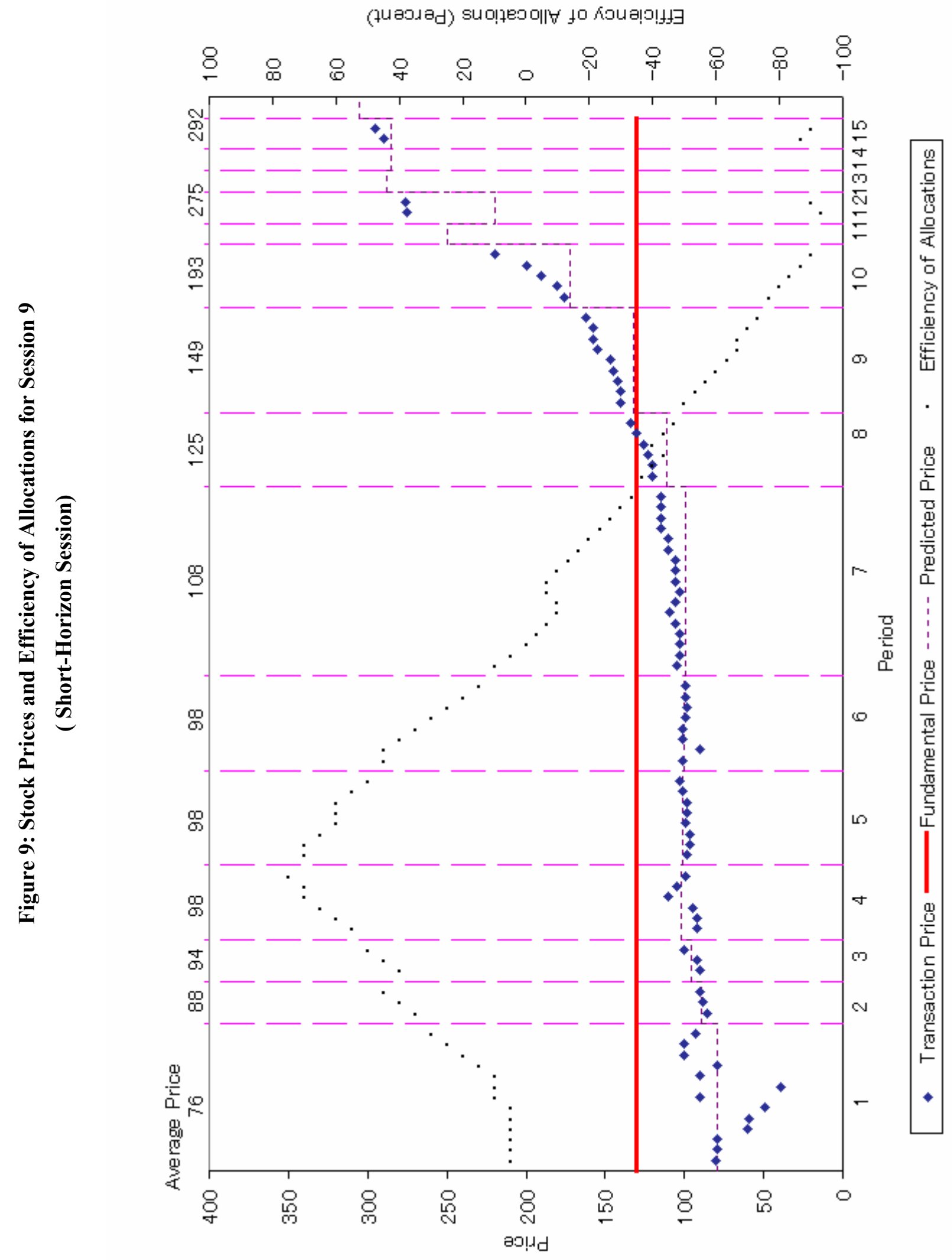




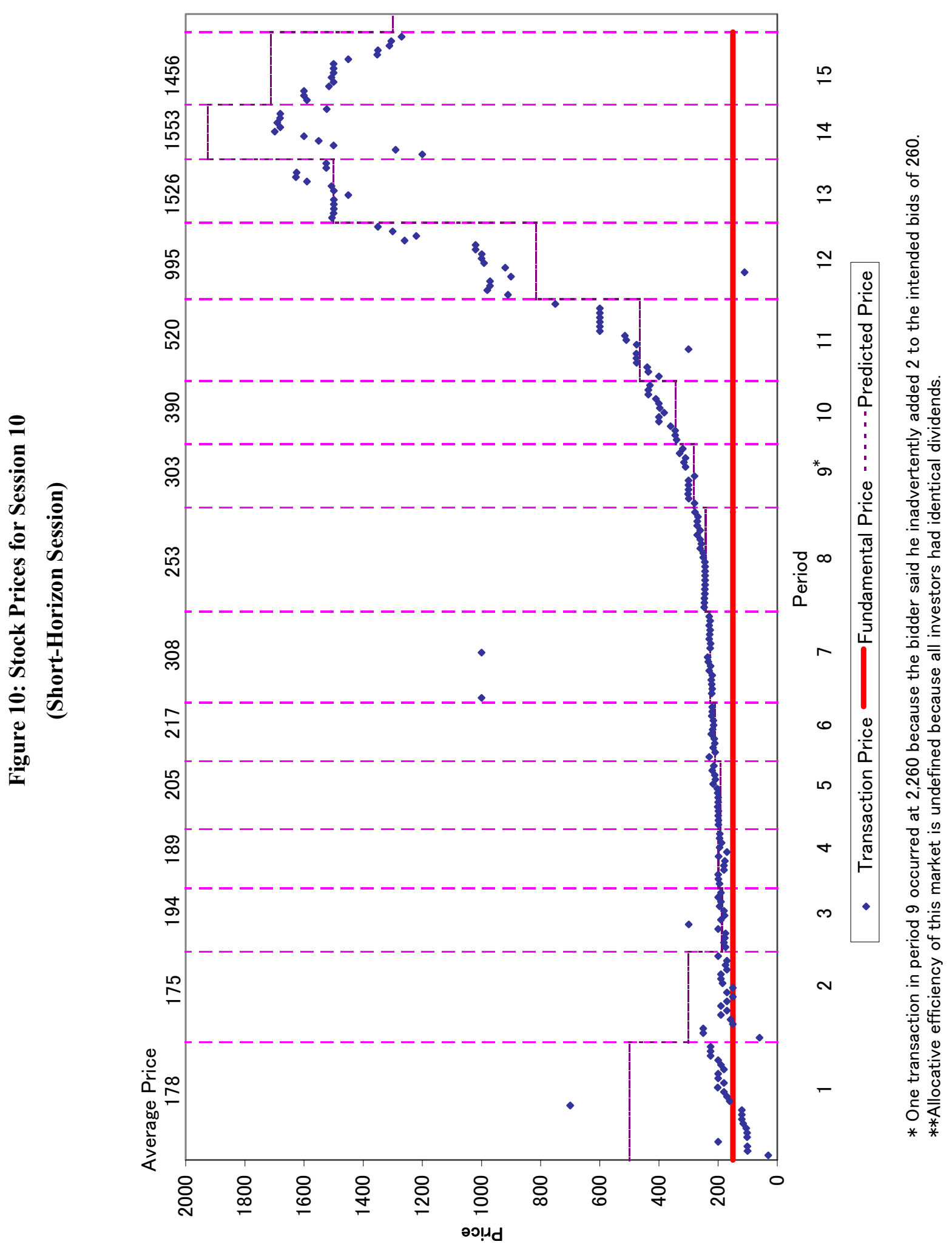




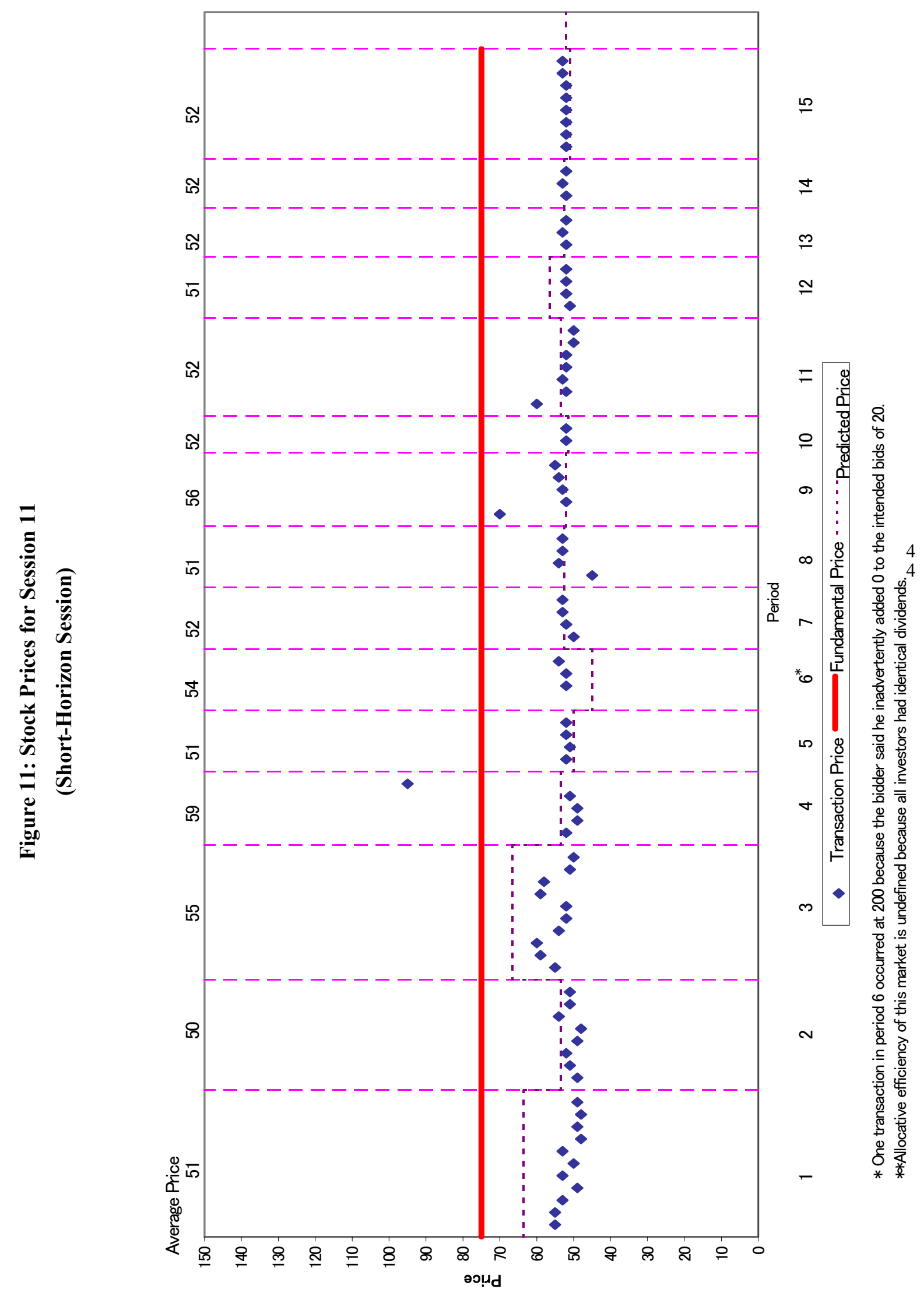




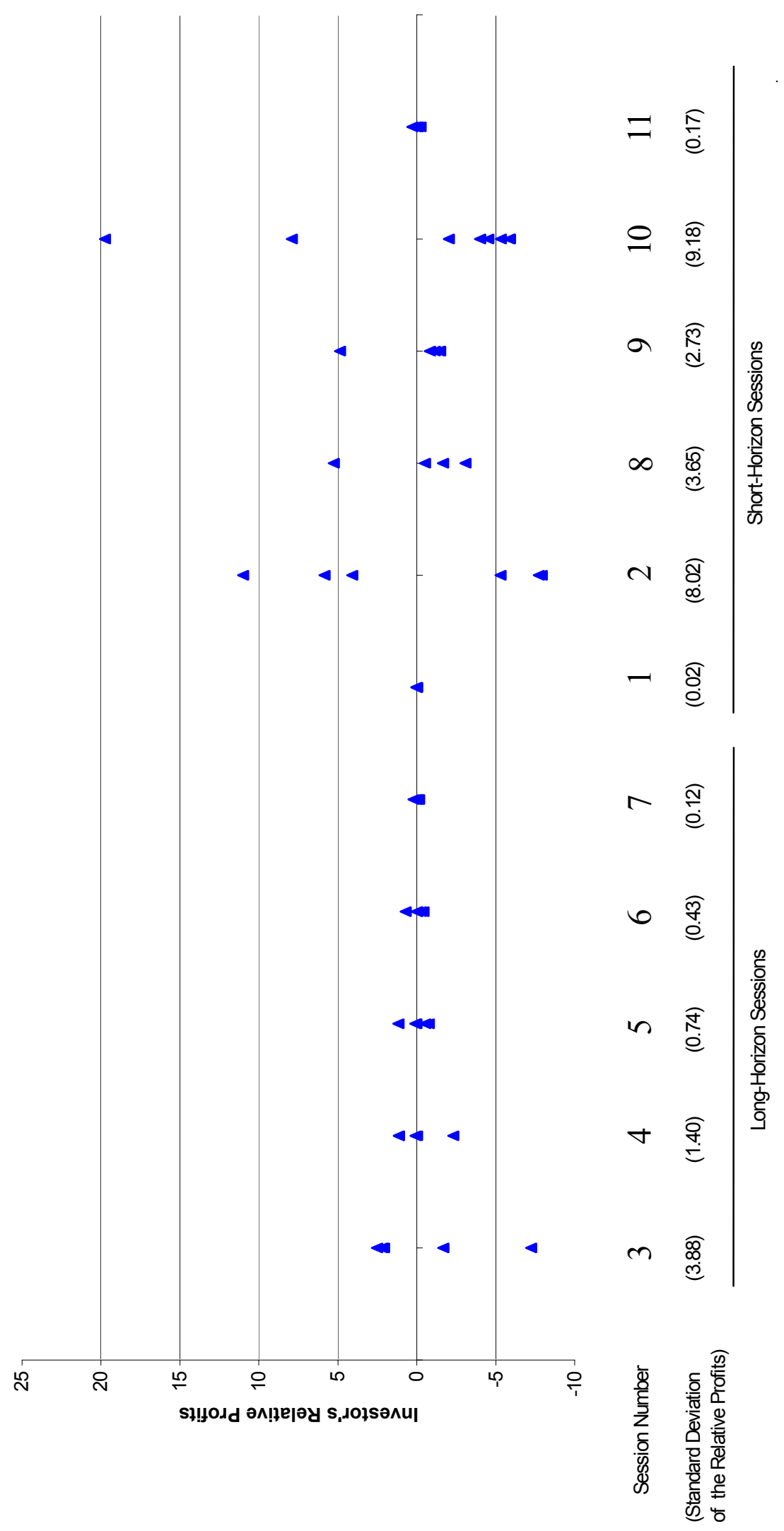

